\title{
Incorporating Active Adjustment into a Financing Based Model of Capital Structure
}

\author{
Neal Maroney \\ Wei Wang \\ Cleveland State University, w.wang24@csuohio.edu \\ M. Kabir Hassan
}

Follow this and additional works at: https://engagedscholarship.csuohio.edu/bus_facpub

Part of the Finance and Financial Management Commons

How does access to this work benefit you? Let us know!

Publisher's Statement

This is the author's version of a work that was accepted for publication in Journal of International Money and Finance. Changes resulting from the publishing process, such as peer review, editing, corrections, structural formatting, and other quality control mechanisms may not be reflected in this document. Changes may have been made to this work since it was submitted for publication. A definitive version was subsequently published in the Journal of International Money and Finance, 90, (2019), 10.1016/j.jimonfin.2018.09.011.

\section{Recommended Citation}

Maroney, Neal; Wang, Wei; and Hassan, M. Kabir, "Incorporating Active Adjustment into a Financing Based Model of Capital Structure" (2019). Business Faculty Publications. 281.

https://engagedscholarship.csuohio.edu/bus_facpub/281

This Article is brought to you for free and open access by the Monte Ahuja College of Business at EngagedScholarship@CSU. It has been accepted for inclusion in Business Faculty Publications by an authorized administrator of EngagedScholarship@CSU. For more information, please contact library.es@csuohio.edu. 


\title{
Incorporating active adjustment into a financing based model of capital structure
}

\author{
Neal Maroney Wei Wang M. Kabir Hassan
}

\begin{abstract}
A B S T R A C T
The conventional partial adjustment model, which focuses on leverage evolution, has difficulty identifying deliberate capital structure adjustments as it confounds financing decisions with the mechanical autocorrelation of leverage. We propose and estimate a financing-based partial adjustment model that separates the effects of financing decisions on leverage evolution from mechanical evolution. The speed of adjustment (SOA) is firmspecific and stochastic, and active targeting of capital structure has a multiplier effect that depends on the size of financial deficit. Overall, we find expected SOA from active rebalancing (30\%) more than doubles what is expected from mechanical mean reversion alone $(13 \%)$.
\end{abstract}

Keywords:

Capital structure

Trade-off theory

Partial adjustment model

Target financing model

Random financing

Speed of adjustment

\section{Introduction}

The use of debt incurs a tradeoff between tax savings and distress costs, which theoretically dictates an optimal capital structure (e.g., Scott, 1976). The Graham and Harvey (2001) survey shows that a great majority of firms do have a target capital structure level or range. Factors such as adjustment costs (Fisher et al., 1989), information asymmetry (Myers and Majluf, 1984), and financial flexibility (Denis and McKeon, 2012; Eckbo and Kisser, 2016) also impact capital structure decisions, sometimes driving leverage away from the target level. ${ }^{1}$ The aggregate effect of these factors is reflected in the speed of adjustment (SOA) at which a firm adjusts its leverage toward the target. A faster SOA indicates greater importance of the tax benefits vs. distress costs tradeoff relative to other considerations.

The partial adjustment model has been the workhorse of the capital structure literature: $d_{t+1}-d_{t}=\lambda\left(d_{t+1}^{*}-d_{t}\right)+\varepsilon_{t}$, where $d_{t}$ and $d_{i+1}$ are the leverage ratios, $d_{t+1}^{*}$ is target leverage, and $\varepsilon_{t}$ is the error term at their respective dates. In this

\footnotetext{
1 Additional factors have been identified in the literature, including alternative tax shields (Schivdasani and Stefanescu, 2010), labor (Matsa, 2010), cash flows (Faulkender et al., 2012), corporate governance (Morellec, Nikolov and Schuthoff, 2012), and sensitivity of cost of equity to leverage deviation (Zhou et al., 2016), among others.
} 
model, $\lambda$ captures the fraction of leverage deviation from target, $d_{t+1}^{*}-d_{t}$, that is eliminated each period, i.e., the speed of adjustment $(S O A)$. In practice, target leverage is often instrumented to be a function of variables known to impact the choice of financial leverage, and the $S O A$ is one minus the leverage autocorrelation coefficient. ${ }^{2}$ Capital structure adjustment under this model is a smooth mean reverting process.

Notwithstanding its widespread use, the partial adjustment model is subject to theoretical and empirical difficulties, thwarting the efforts to correctly quantify the SOA (e.g., Chang and Dasgupta, 2009; Hovakimian and Li, 2012). While a firm's capital structure is determined by financing decisions, the partial adjustment model focuses only on the evolution of overall leverage and confuses mechanical mean reversion of leverage (e.g., Chen and Zhao, 2007) with active financial decision making. It also fails to recognize the crucial role of financial surplus in financing decisions (e.g., Leary and Roberts, 2005; Denis and McKeon, 2012; Faulkender et al., 2012). In addition, the model has suffered from an array of econometric problems (e.g., Iliev and Welch, 2010) and assumes capital structure adjustment is smooth and uniform across firms (Leary and Roberts, 2005).

This paper develops and estimates a financing-based capital structure model that has the power to distinguish between mechanical adjustment and meaningful rebalancing. The stochastic SOA depends on the size of the financial deficit/surplus as well as on the probability of issuing/repurchasing securities to resolve deviations from target leverage. Consistent with dynamic trade-off theory, estimation of this target financing model shows that the effect of targeting on leverage dynamics doubles the mechanical effect.

The speed of adjustment has been viewed as "perhaps the most important issue" in capital structure research (Huang and Ritter, 2009). Faster adjustment means maintaining target leverage is more important in corporate decision making. Researchers, using the partial adjustment model, estimate a SOA which varies substantially depending on ever more robust econometric methods. ${ }^{3}$ Comparisons based on Monte Carlo simulations conducted by Flannery and Hankins (2013) and Dang et al. (2015) indicate that reasonable estimates of SOA seem to be between $17 \%$ and $26 \%$. The validity of such estimates of SOA, however, has been an issue of debate. Among other critiques, the estimated SOAs may be explained by mechanical mean reversion and have little behavioral content (Iliev and Welch, 2010). Chang and Dasgupta (2009) show a positive autocorrelation in leverage arises from a random financing model or from the "neutral mutation" view of Miller (1977), where no target exists. The SOA estimate under mechanical mean reversion, which depends on the size of the financial deficit facing the firm, is around $13 \%$ in our data. ${ }^{4}$

To illustrate mechanical mean reversion, consider a randomly financed firm where issuance decisions are determined by flips of a fair coin. Issue equity if heads, debt otherwise, and record the resulting series of debt ratios arising from successive flips. The expected leverage ratio will be one-half. While the process converges to its mean, the asymmetric influence of financing on the leverage ratio creates positive correlation. By construction, with leverage nearing one, added equity has a larger impact on the ratio than added debt, and vice versa for leverage nearing zero. ${ }^{5}$ As a result, successive changes in leverage tend to follow each other. There is no active rebalancing in this example, yet a positive SOA results. Thus, a positive autocorrelation in leverage ratio may arise from both active leverage targeting and mechanical mean reversion, and the SOA estimate from the conventional partial adjustment model is unable to single out the active targeting effect. Empirical formulations of the model thus far have largely failed to formally address this issue. ${ }^{6}$

In this paper the target financing model we propose differentiates targeting behavior from mechanical mean reversion by allowing for capital structure targeting in the Chang and Dasgupta (2009) framework. To incorporate targeting, we let the likelihood of debt/equity issuance depend on leverage deviation from target level. If achieving targeted capital structure is an important consideration, then an under- (over-) levered firm would be more likely to issue debt (equity) and/or repurchase equity (debt), which in turn leads to changes in the leverage ratio. The resulting model has a partial adjustment form and gives a comprehensive measure of the SOA, yet enables the separation of targeting behavior from the mechanical autocorrelation caused by financial deficits. The model is comparable in form to the conventional partial adjustment model, but the SOA now varies by firm and over time and is expressed as the product of two effects: the mechanical adjustment speed assuming random financing and the additional speed due to targeting behavior. As the model nests random financing as a possibility, it constitutes an informative test of the trade-off theory of capital structure.

We base our empirical exploration on a sample of 140,731 U.S. Compustat firm-year observations spanning 1970-2010.? As target leverage is inherently unobserved, we instrument it with predictions of lagged firm characteristics in a fixed firm and

\footnotetext{
${ }^{2}$ Rearrange the model $d_{t+1}=\lambda d_{t+1}^{*}+(1-\lambda) d_{t}+\varepsilon_{t}$ to see that $1-\lambda$ is the coefficient on lagged leverage.

3 Huang and Ritter (2009) and Elsas and Florysiak (2015), among others, discuss the econometric approaches to estimating SOAs using the partial adjustment framework

${ }^{4}$ Our sample average financial deficit is $k=14.7 \%$ which corresponds to speed of adjustment: SOA $=\frac{k}{1+k}=12.8 \%$, using the Chang and Dasgupta (2009) model.

5 Define the debt ratio as $\frac{D}{A}$, where assets equal debt plus equity: $A \equiv D+E$. The partials w.r.t. equity and debt are,$d_{E}^{\prime}=-\frac{d}{A}$, and $d_{D}^{\prime}=\frac{1-f}{A}$, showing that the differential effect of equity and debt depends on initial leverage.

${ }^{6}$ Iliev and Welch (2010) simulate mechanical mean reversion using a random financing strategy similar to Chang and Dasgupta (2009) and compare the SOA estimates in this NULL sample and in the real sample, attempting to single out the SOA due to active adjustments. Differing from Iliev and Welch (2010), we explicitly model targeting behavior and its effect on leverage evolution.

There is a plethora of literature that examines capital structure dynamics in the international setting, including but not limited to Drobetz and Wanzenried (2006), De Jong, Kabir and Nguyen (2008), Fan, Titman and Twite (2012), Oztekin and Flannery (2012), and Huang and Shen (2015). Overall they find firms exhibit incomplete and heterogeneous adjustments, in a way similar to the U.S firms. We use the U.S. sample to follow Chang and Dasgupta (2009) as well as to avoid potential complexity due to diverse legal and institutional environments. The existence of mechanical mean reversion of leverage ratios does not depend on legal and institutional environments and hence our model would have the similar effect of telling apart deliberate from spurious targeting in the international setting.
} 
time effects regression, per the prescription of DeAngelo and Roll (2015) and the characteristics contained in Flannery and Rangan (2006). Next, we estimate the SOA from our financing-based partial adjustment model to gauge the relationship between issuance decisions and leverage evolution. Unlike its discrete counterparts in the literature (Huang and Ritter, 2009), this financing model gives an expected SOA and the parameterization of the probability of issuance does not require an observed issuance indicator.

Consistent with deliberate targeting, we find a positive association between issuance decisions and leverage deviations in our sample. An under-levered firm is more likely to issue debt, and an over-levered firm is more likely to issue equity when facing a financial deficit. The relation between issuance propensity and leverage deviation is economically significant: when leverage deviation increases by one standard deviation (about 0.12 ), the probability of issuing securities toward correcting this deviation increases by nine percent. Targeting has a multiplier effect, in the sense that firms with larger financial deficits have shorter half-lives of adjustment than firms with small deficits. For an average firm, SOA with active rebalancing more than doubles what is expected from mechanical mean reversion alone, increasing from $13 \%$ under random financing to almost $30 \%$ when targeting is considered. In addition, the target financing model is able to distinguish deliberate targeting from leverage autocorrelation caused by pecking order financing (Shyam-Sunder and Myers, 1999).

The rest of the paper is organized as follows: Section 2 presents the target financing model; Section 3 details estimation of the model; Section 4 explains data selection, formation of the target leverage measure, and construction of the simulated data; Section 5 discusses empirics; and Section 6 concludes.

\section{Model}

We build on the random financing model of Chang and Dasgupta (2009) to allow a relation between leverage deviation and the probability of issuance. Assets at time $t+1$ are written as $A_{t+1}=A_{t}(1+g)=A_{t}(1+n e i+n d i+$ re $)$, where assets grow on the base $A_{t}$ at the rate $g$. The growth comes from actively managed issuance/repurchase of equity and debt, $k=n e i+n d i$, and retained earnings, re, all expressed as a ratio relative to $A_{t}$. We omit time subscripts for the above ratios for clarity. We follow Chang and Dasgupta (2009) and assume re is zero for all firms ${ }^{8}$ and that the firm chooses to finance the deficit/surplus either with debt issuance/retirement with probability $p$ or equity issuance/repurchase with probability $(1-p)$. Debt will then grow to $D_{\mathrm{t}+1}=D_{\mathrm{t}}+A_{\mathrm{t}} k$ when debt financing is chosen or remain unchanged when equity is chosen. Two scenarios of the debtto-asset ratio, $d_{t+1}=D_{t+1} / A_{t+1}$, result from this scheme,

$$
d_{t+1}=\left\{\begin{array}{cc}
\frac{d_{t}}{(1+\mathrm{k})}+\frac{k}{(1+\mathrm{k})} & \text { with Prob }=p \\
\frac{d_{t}}{(1+\mathrm{k})} & \text { with Prob }=1-p .
\end{array}\right.
$$

Debt ratios, therefore, are autocorrelated,

$$
E\left(d_{t+1} \mid t\right)=\frac{k}{(1+k)} p+\frac{1}{1+k} d_{t} .
$$

Eq. (2) shows a model that describes that leverage evolution should have a financing decision variable on the right-hand side, and, more importantly, the autocorrelation of the leverage ratio contains a factor that is independent of the financing decision. Researchers estimating a partial adjustment model would observe a coefficient on lagged leverage of $\frac{1}{1+k}$ when the financing decision is unrelated to leverage deviation or, equivalently, when target leverage is nonexistent or irrelevant. In other words, as $k$ is positive on average, firms exhibit a "speed of adjustment", $\lambda_{r}=\frac{k}{1+k}$, even when financing is completely random. The conventional partial adjustment model hence confounds active rebalancing with random financing.

In order to distinguish targeting from random financing, we propose a target financing model that allows for the probability of issuance/repurchase of debt to depend on deviations of actual leverage, $d_{t}$, from target leverage, $d^{*}$. We model the probability of issuance/repurchase as logistic.

$$
P\left(d_{\mathrm{t}}\right)=\frac{1}{1+e^{-z_{d_{t}}}}, z_{d_{t}}=\ln \left(\frac{d^{*}}{1-d^{*}}\right)+\frac{\mathrm{k}}{|\mathbf{k}|} \theta\left(d^{*}-d_{\mathrm{t}}\right) .
$$

The random financing model assumes $\theta$ is zero. As Chang and Dasgupta (2009) demonstrate, when the debt ratio equals the probability of debt issuance, successive changes in leverage are expected to be zero,

$$
\mathrm{E}\left(d_{t+1}-d_{t}\right)=\frac{k}{1+k}\left[P\left(d_{t}\right)-d_{t}\right] .
$$

In the long run, if the size of the financial deficit is the same, no matter whether financed by debt or equity, all firms must issue/repurchase with a probability equal to the target ratio $d^{*}$. This property dictates the intercept in $z_{\mathrm{t}}$ to be $\ln \left(\frac{\mathrm{d}^{*}}{1-d^{*}}\right)$. $\theta$ is the

\footnotetext{
${ }^{8}$ Retained earnings is omitted for clarity because its inclusion does not materially alter the model. The average retained earnings to assets from Table 1 is 0.007 , consistent with Chang and Dasgupta (2009). In our empirical work and simulations we relax the assumption of zero retained earnings and find a very minor impact on results.
} 
target financing parameter. When $\theta$ is positive, targeting behavior exists where an under-levered firm, $\left(d^{*}-d_{t}\right)>0$, tends to issue debt, while an over-levered firm, $\left(d^{*}-d_{\mathrm{t}}\right)<0$, tends to issue equity. ${ }^{9}$ The term $k / k \mid$ picks up the sign change to allow for targeting behavior in the face of financial surpluses.

Adjustment speed from a target financing model is faster than random financing would predict. The speed of adjustment in a stochastic setting may be defined by how much the expected change in debt ratio responds to deviations from target level. Take Eq. (4) and differentiate w.r.t. $d_{t}$ to get the SOA expression, ${ }^{10}$

$$
\lambda\left(z_{d_{t}}\right)=\frac{\partial E\left(d_{t+1}-d_{t}\right)}{\partial\left(d^{*}-d_{t}\right)}=\left[1+\frac{k}{|k|} \theta f\left(z_{d_{t}}\right)\right] \lambda_{r}
$$

where $f\left(z_{d_{t}}\right)$ is the issuance probability density evaluated at the debt ratio $d_{t}$ and $\lambda_{r}=\frac{k}{1+k}$ is the random financing SOA. The speed of adjustment is, thus, the combined effect of mechanical mean reversion, $\lambda_{r}$, and managerial intervention that is a function of the initial leverage deviation, $d^{*}-d_{t}$. When targeting behavior is present $(\theta>0)$ the speed of adjustment is greater than that under random financing.

Comparative statics show that the speed of adjustment $\lambda\left(z_{d_{t}}\right)$ is increasing in (1) the target financing $\theta ;(2)$ the extent of leverage deviation, $\left|d^{*}-d_{t}\right|$, given a positive $\theta$, that is, in the presence of targeting behavior; and (3) the deficit, $k$. There is heterogeneity in the SOA because financial deficits and target leverage may vary by firm and over time. ${ }^{11}$ When targeting behavior is present, the expected half-life of leverage deviation is shorter than under random financing and is a function of initial leverage deviation, $d^{*}-d_{\mathrm{t}}$. To show the expected half-life, it is necessary to derive the partial adjustment representation of the model. We write the conditional expectation from date $=t$ as

$$
E_{t}\left(d_{t+1}\right)=\frac{k P\left(d_{t}\right)}{1+k}+\frac{1}{1+k} d_{t},
$$

and use a first order approximation for the probability of issuance in (6) around target leverage, ${ }^{12}$

$$
P\left(d_{t}\right)=P\left(d^{*}\right)+\theta \frac{k}{|k|} f\left(z_{d^{*}}\right)\left(d^{*}-d_{t}\right)=d^{*}+\theta \frac{k}{|k|} d^{*}\left(1-d^{*}\right)\left(d^{*}-d_{t}\right),
$$

where $f\left(z_{d^{*}}\right)$ is the issuance probability density, evaluated at target leverage $\mathrm{d}^{*} .{ }^{13}{ }^{14}$ Substitute (7) into (6) and rearrange terms to get,

$$
E_{t}\left(d_{t+1}\right)=\lambda\left(z_{d^{*}}\right) d^{*}+\left[1-\lambda\left(z_{d^{*}}\right)\right] d_{t},
$$

where,

$$
\lambda\left(z_{d^{*}}\right)=\left[1+\frac{k}{|k|} \theta \mathrm{d}^{*}\left(1-\mathrm{d}^{*}\right)\right] \lambda_{\mathrm{r}},
$$

which is a partial adjustment representation of the model. Rearrange (8) and iterate forward $j$ periods to get,

$$
E_{t}\left(d_{t+j}\right)=d^{*}-\left[1-\lambda\left(z_{d^{*}}\right)\right]^{j}\left(d^{*}-d_{t}\right)
$$

expected leverage $j$ periods ahead. To find the half-life $(\Lambda)$, set expected deviation to half of the initial value,

$$
d^{*}-E_{t}\left(d_{t+j}\right)=0.5\left(d^{*}-d_{t}\right)
$$

insert (10), and solve for time, (i.e., $j$ ),

$$
\Lambda=\frac{\ln (0.5)}{\ln \left[1-\lambda\left(z_{d^{*}}\right)\right]} .
$$

If $\theta=0$, the half-life for random financing results. For any positive $\theta$ for which unconditional expectations exist, i.e., $0<\lambda\left(z_{d^{*}}\right)<1$, the half-life is shorter relative to random financing.

We calibrate the effect of targeting behavior on top of mechanical mean reversion assuming values for the target financing parameter, $\theta$, as well as financial deficit, $k$. The half-life of leverage deviations is shown in Figs. 1 and 2 . Fig. 1 shows that

\footnotetext{
${ }^{9}$ Theoretically a negative $\theta$ is predicted if a firm follows a market timing strategy. However, most empirical evidence points to a positive $\theta$.

10 Here the differential in the denominator uses $\Delta d=\left(d-d^{*}\right)$, so $\left(d^{*}-d_{t}\right)=-\Delta d$.

11 Empirically, heterogeneity in SOA is documented in recent literature such as Faulkender et al. (2012), Mulkherjee and Wang (2013), and Zhou et al. (2016).

12 The approximation uses $z_{d^{*}}=\alpha+\theta\left(d^{*}-d_{\mathrm{t}}\right)$. After linearization, $\alpha$ is set to $\ln \left(d^{*} /\left(1-d^{*}\right)\right)$ to avoid needless complication.

13 The issuance probability density $f\left(z_{d^{*}}\right)=d^{*}\left(1-d^{*}\right)$ because $z_{d^{*}}=\ln \left(\frac{d^{*}}{1-d^{*}}\right)$, and $f\left(z_{d^{*}}\right)=\frac{e^{-z_{d^{*}}}}{\left(1+e^{-z_{d^{*}}}\right)^{2}}$.

14 This approximation is accurate to less than one percent at one standard deviation with our model and data. We evaluated the approximation error by comparing the logistic distribution probability to the approximated one (Eqs. (3) \& (7)) empirically evaluating the resulting error at sample average leverage of 0.437 and at our estimated $\theta$ of 5.364. A deviation, $\Delta d=d^{*}-d$, that is one standard deviation (0.120) from its mean (0.0075), gives an error of 0.0008 and a deviation that is minus one standard deviation from its mean gives an error of 0.0094 . Error worsens with negative deviations, but total probability is higher. At the 10 th percentile $(-0.134)$ the error is 0.0143 while at the 90 th percentile $(0.146)$ the error is -0.0002 .
} 
half-life monotonically decreases with $\theta$, given the sample average financial deficit of $14.7 \%$ and the sample median financial deficit of $8 \%{ }^{15}$ Using the sample average deficit, when $\theta$ is set to our estimate of 5.364 , half-life shortens from 5 years with random financing $(\theta=0)$ to under 2 years with target finance--a $60 \%$ reduction. The effect of the size of financial deficits on half-life is shown in Fig. 2. When $k$ increases from $5 \%$ to $80 \%$ of assets, adjustment is much quicker both under random $(\theta=0)$ and target finance $(\theta=5.4)$, but still half-life shrinks much more with target financing. The financial deficit is part of the baseline SOA, so Fig. 2 picks up the interaction of financial deficit and target financing parameter on the full SOA.

\section{Estimation}

We can estimate the target financing parameter, $\theta$, from both the original issuance choice-based and linearized financing models. While the issuance choice models with Logit and Probit specifications (in Appendix B) require a binary issuance indicator and only provide the probability of issuance piece of the leverage evolution puzzle, the linear target financing model provides a complete picture of leverage evolution, with the added advantage of not requiring the researcher to observe an issuance indicator for estimating $\theta$.

The target financing parameter $\theta$ is estimated in a partial adjustment framework, explicitly allowing for variation in speed of adjustment across firms and over time. In its empirical form, we use the expectation given in (8) to run ordinary least squares because the model is provided in firm-specific deviation form. Start with deviations from the conditional expected leverage as

$$
d_{t+1}-E\left(d_{t+1}\right)=\gamma_{0}+\varepsilon
$$

Substitute in expectations to get

$$
d_{t+1}-d_{t+1}^{*}+\left[1-\lambda\left(z_{d^{*}}\right)\right]\left(d_{t+1}^{*}-d_{t}\right)-\gamma_{0}=\varepsilon
$$

which is a partial adjustment version of the model, where

$$
\lambda\left(z_{d^{*}}\right)=\left[1+\frac{k}{|k|} \theta d_{t+1}^{*}\left(1-d_{t+1}^{*}\right)\right]\left(\frac{k}{1+k}\right)
$$

is the SOA, evaluated at target leverage. The expression in (13b) can be rearranged into a simple regression form:

$$
\Delta_{1}=\gamma_{0}+\theta \Delta_{0}+\varepsilon,
$$

where $\Delta_{1}=d_{t+1}-d_{t}-\frac{k}{1+k}\left(d_{t+1}^{*}-d_{t}\right)$ and $\Delta_{0}=\frac{k}{1+k} \frac{k}{|k|} d_{t+1}^{*}\left(1-d_{t+1}^{*}\right)\left(d_{t+1}^{*}-d_{t}\right)$. The coefficient $\gamma_{0}$ is the intercept, $\varepsilon$ is a mean zero error term, and $k$ is the financial deficit that may vary across firms and over time. We perform robustness checks, discussed in details later, using various definitions of $k$ and find the definition does not alter our conclusions. Notice that $\Delta_{1}$ is the error from a partial adjustment model with random financing. The right-hand side, $\theta \Delta_{0}$, captures the total effect of leverage deviations on the probability of issuance, i.e., the marginal effect of leverage deviations on the probability of issuance, $\frac{\partial \mathrm{p}}{\partial\left(d_{t+1}^{*}-d_{0}\right)}=\frac{k}{|k|} \theta f\left(d_{t+1}^{*}\right)=\frac{k}{|k|} \theta d_{t+1}^{*}\left(1-d_{t+1}^{*}\right)$, times the deviation $\left(d_{t+1}^{*}-d_{t}\right)$. This model is estimated with OLS and reported with panel robust standard errors. In the same spirit as Faulkender et al. (2012), the differences in intercept terms across firms are accounted for, because variables in (T1) are either differences in leverage or deviations from target leverage, based on fixed effects predictions.

\section{Data}

Our sample is from the Compustat Industrials Files and includes firms from 1970 to 2010 . We select the sample in a manner consistent with the literature, requiring that each firm have complete data at time $t$ and time $t+1$, except for R\&D expense, which is commonly missing in Compustat data. Financials (SIC codes 6000-6900) and utilities (SIC code 49004999) are excluded. Book values are converted into 2000 constant dollars (only when used as levels), and firms must have at least one million dollars in real total assets. Included firm years must have positive book equity, sales, and common shares outstanding. Penny stocks are excluded, so firms must have common share prices of at least one dollar at the fiscal year end. This initial set of criteria gives 142,842 firm-year observations.

Given that financing directly alters a firm's book capital structure, but its connection to market value of equity is less clear, our investigation focuses only on book leverage. ${ }^{16}$ Data definitions follow Chang and Dasgupta (2009). Book debt is defined as debt $=$ total liabilities $(L T)+$ preferred stock (PSTK)-deferred taxes (TXDB)- debt convertible to common stock (DCVT). Book equity is $b e q=$ totalassets $(A T)$ - debt, total assets minus debt. Leverage is then $b l e v=\operatorname{debt} / A$, debt to total assets.

Financial deficits are defined based on the balance sheet. The need for external financing, $k$, is the change in total assets minus changes in retained earnings. A financial deficit arises when $k>0$ and a surplus arises for $k<0$. External financing

\footnotetext{
${ }^{15}$ Half-life also depends on target leverage. Higher target leverage shortens half-life for a given $\theta>0$. The Figures assume a near sample average leverage of $45 \%$.

${ }^{16}$ For a thorough discussion of this issue, see Chang and Dasgupta (2009), p1779.
} 


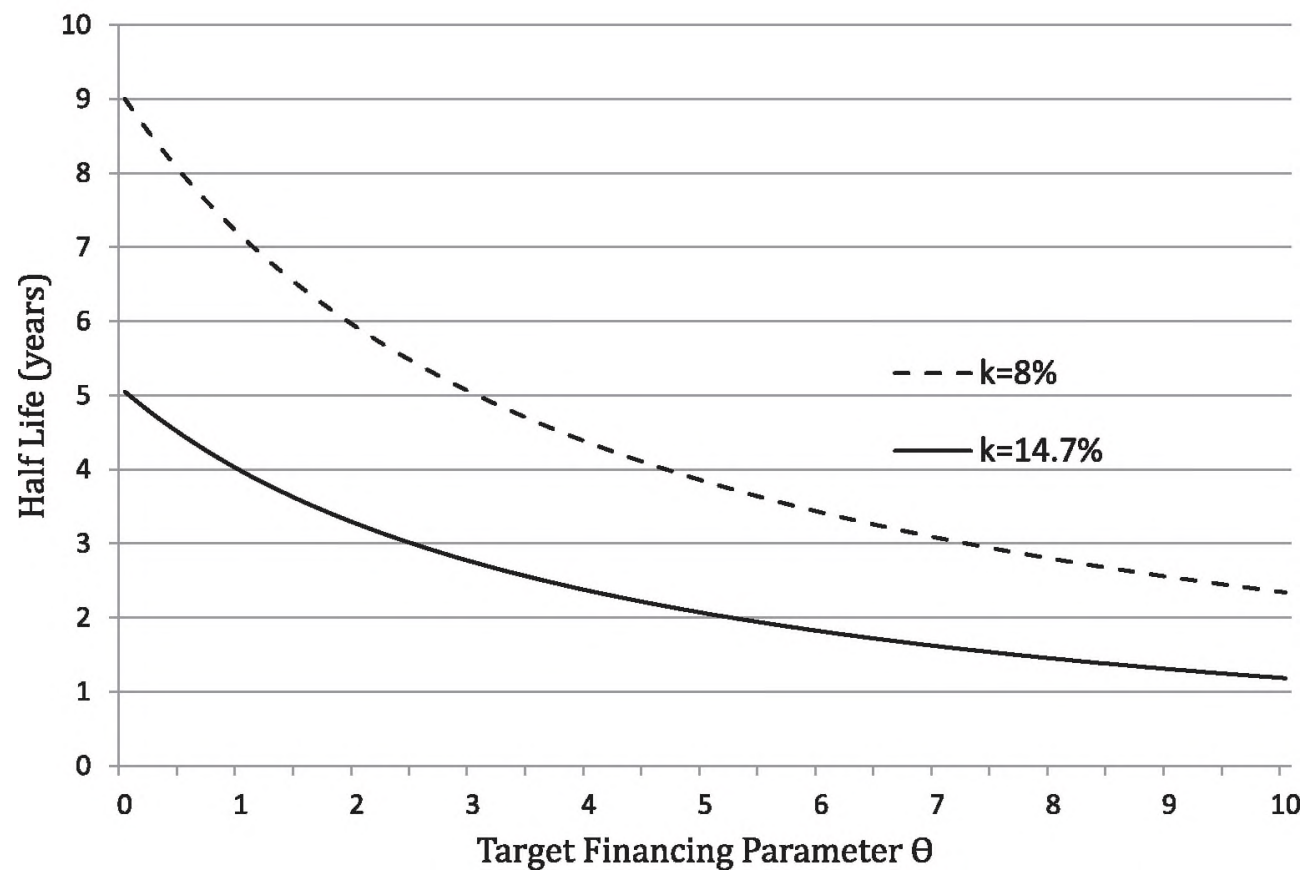

Fig. 1. Half-life and target financing parameter, $\theta$.

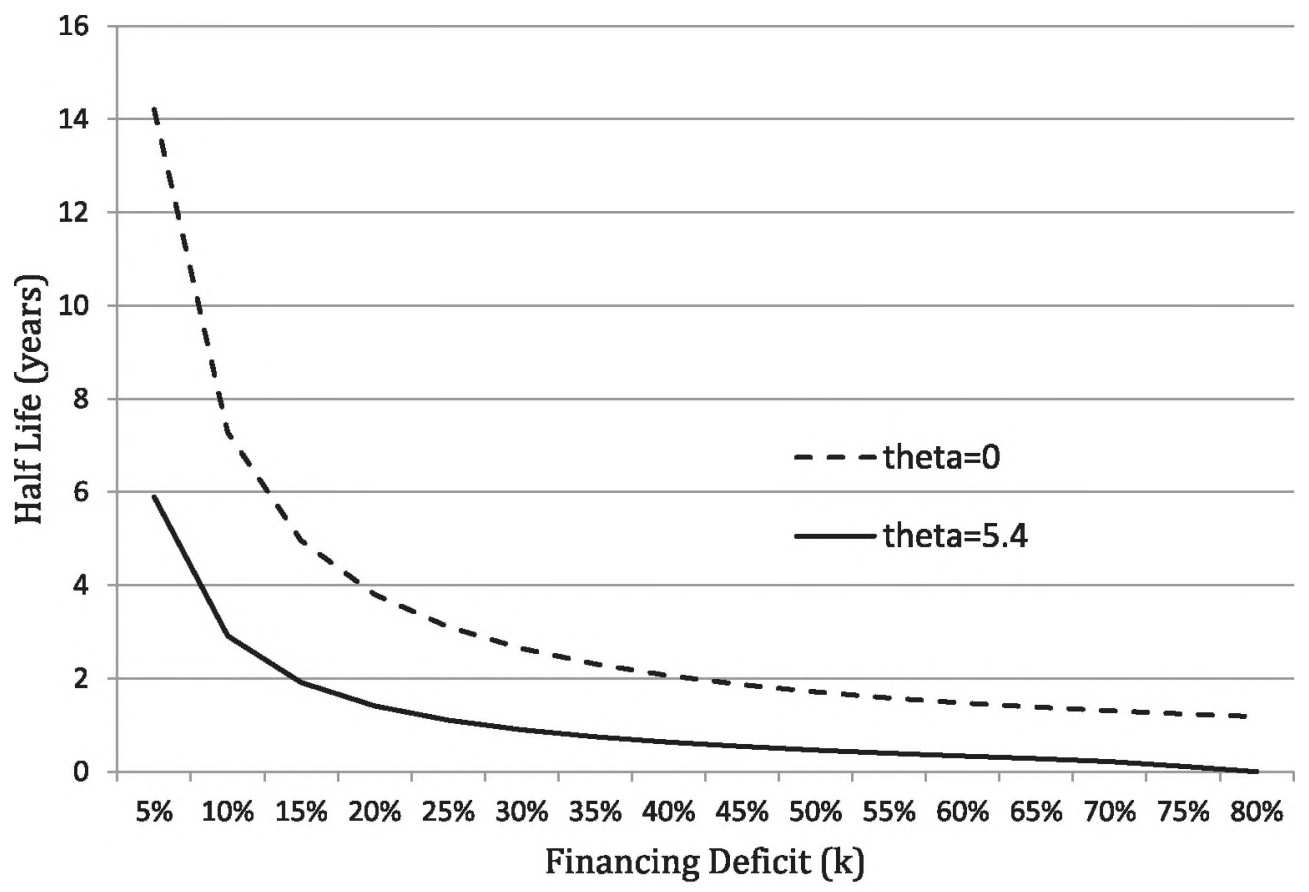

Fig. 2. Half-life and financial deficit, $k$.

needs may be satisfied by equity and/or debt issuance, so the deficit $k$ is also the sum of net equity and debt issues, $k=n e i+n d i$. Net equity issues are defined as the change in book equity minus the change in retained earnings. Net debt issues are defined as the changes in assets, less changes in retained earnings and net equity issues. Rather than their levels, we define all these quantities as a portion of total assets at $t$.

To weed out extreme observations in financing ratios and to be able to calculate needed quantities, we restrict the changes in retained earnings to assets, re, financial deficit to assets, $k$, and asset growth, $g$, to be above negative $95 \%$ and 
below 300\%. This requirement removes 2,111 firm-year observations. To minimize the effect of extreme observations and data errors in the final sample of 140,731 observations, both net debt and equity issues are winsorized by $0.5 \%$ in each tail. Ratios, defined below, used as firm characteristics, such as market-to-book, profitability, deprecation, tangibility, and R\&D are also winsorized by the same tail fraction.

Because target leverage ratios are unobserved, it is standard in the literature to instrument target leverage at time $t+1$, $d_{t+1}^{*}$, with the predictions from a regression of leverage on lagged firm characteristics found to influence capital structure decisions:

$$
d_{t+1}^{*}=\boldsymbol{\beta} \boldsymbol{Z}_{\boldsymbol{t}},
$$

where $\boldsymbol{Z}$ is a vector of firm characteristics, including firm size (size), market-to-book ratio ( $m t b$ ), profitability (profit), asset tangibility (tangi), depreciation tax shield (depre), R\&D expense $(r d)$, a dummy indicating the availability of R\&D expense (rdd), as well as industry median leverage (indd), and fixed firm and time effects. ${ }^{17}$ Firm size is measured by the log of total assets (in constant 2000 dollars). The market-to-book ratio is equal to the sum of debt and market equity, $m e q=(P R C C F \times C S H O)$, divided by the sum of debt and book equity. Profitability, tangibility, and depreciation are measured by earnings before interest, taxes, and depreciation (OIBDP), net property, plant, and equipment (PPENT), and depreciation and amortization (DP), respectively, scaled by total assets. R\&D expense is scaled by sales. Indd is the historic median leverage ratio for the 2-digit SIC industry in the previous five years and time effects is a vector of fiscal year dummy variables.

Appendix A presents summaries of firm characteristics and the fixed effects estimation of the regression-based target measure, $d_{t+1}^{*}$. Firms in our sample have an average book leverage of 0.437 with a standard deviation of 0.203 . Other firm characteristics are also consistent with prior literature, including $45 \%$ of firm-year observations reporting R\&D expenses. All explanatory variables load significantly in the regression, with the exception of the dummy variable ( $r d d$ ) that indicates the availability (or lack thereof) of R\&D information.

We examine the characteristics of our target measure as well as the correlations between the target estimate and the actual leverage ratio in untabulated results. The mean and median of the target are very close to the mean and median of the actual leverage ratio. The unconditional autocorrelation of leverage ratio is 0.873 and that of the demeaned leverage is 0.677 . Note that this indicates that if we run a regression of leverage on lagged leverage we will get an "SOA" of 0.127 if the pooled OLS estimator is used or 0.323 if the fixed effects are controlled for, both of which are consistent with the literature. The target leverage (the leverage deviation) is positively (negatively) correlated with actual leverage ratios.

\subsection{Financing decisions}

Financing decisions are often not binary in nature, as debt and equity are used at the same time to achieve external financing goals. As shown in Appendix B, Table B1, Panel A, there are nine possible combinations of debt and equity decisions, with the "pure debt and no equity" case accounting for only 9.1 percent of all scenarios while the "pure equity and no debt" case accounts for merely 0.6 percent. In contrast, debt issuance is accompanied by equity issuance 43.7 percent of time and by equity repurchases 14.8 percent of time.

Financing models require us to know the financial deficit, $k$, and asset growth, $g$. Appendix B, Table B1, Panel B shows that asset growth averages 14.7 percent, with a large standard deviation of 34.6 percent. To finance asset growth, funds may come from retained earnings and external capital. Retained earnings averages 0.7 percent of assets but exhibits substantial variation, with a standard deviation of 16 percent of assets. The difference between asset growth and retained earnings constitutes the financial deficit, which averages 14 percent of assets.

\subsection{Simulated data}

We seek to construct a panel dataset of debt ratios where the way firms are financed is random to verify that our empirical estimates of $\theta$ are not the result of mechanical mean reversion, inconsistency of estimation with short time series and lagged dependent variables, or other properties of how leverage evolves. Chang and Dasgupta (2009) generate economically equivalent coefficients on lagged leverage, as seen in the literature, in simulations assuming random financing; our simulated data reproduces their results.

Start with the identity for the book debt-to-asset ratio at time $t+1$,

$$
d_{t+1} \equiv \frac{n d i+d_{t}}{(1+g)},
$$

where asset growth $g=n e i+n d i+r e$ is the sum of three financing variables: net equity issuance, net debt issuance, and new retained earnings to assets. The three financing variables are assumed to be log normal iid variables whose moments

\footnotetext{
${ }^{17}$ Close variations of our specification are used in a number of studies including Rajan and Zingales (1995), Hovalkimian et al. (2001), Fama and French (2002), Hovakimian (2004), Flannery and Rangan (2006), Lemmon, Roberts, and Zender (2008), Faulkender et al. (2012), and more. Chang and Dasgupta (2009) also include a lagged stock return, which we do not because of little added predictive value compared to 17,889 firm years deleted by making the availability of lagged stock return a data requirement.
} 
are randomly selected from a table containing the empirical moments of all firms. We build a time series of debt ratios for each firm $i$ of a length equal to that found in the data by starting with the real initial debt ratio $d_{t, i}$. We then construct time series using draws of the financing variables such that they obey the empirical limits of asset growth. If a set of draws do not obey the feasibility conditions, it is rejected and redrawn until a set does.

Specifically, for the simulation a table is first built containing the empirical mean/standard deviation pairs of each financing variable for all firms (variables are first transformed by adding one and taking logs). Asset growth, $g$, is formed for a synthetic firm $i$ by independently drawing a mean/standard deviation pair of each of the three financing variables from the table. This is done to avoid mimicking the cross-sectional correlation of the means found in the real data because these correlations may themselves shape active decision making that we seek to exclude in simulations. ${ }^{18}$ These moments then serve as the basis of random draws in constructing a synthetic firm's time series of debt ratios. If a particular firm's set of mean/standard deviation pairs does not result in a feasible time series of debt ratios after 50 tries, then another set of mean/standard deviation pairs are chosen from the table and the process is repeated until a feasible time series is found.

For internal consistency in our simulations, we use a naive target debt ratio measure in regressions. Our real-data estimation uses a fixed effects regression measure based on firm characteristics. The pseudo target used in simulations is from a fixed effects regression on our synthetic dataset where characteristics play no role in explaining debt ratios. The target becomes a firm's sample mean with noise produced by a normally distributed random variable with a variance equal to the between variance of the dataset, trimmed to be in the zero to one range.

\section{Results}

\subsection{Partial adjustment model}

We estimate the conventional partial adjustment model to demonstrate that the coefficient on lagged leverage is simply mechanical and does not constitute an informative test of capital structure theories. We also show that the coefficient on target capital structure is significant and informative in explaining capital structure change. The empirical version of the partial adjustment model is

$$
d_{t+1}=\gamma_{0}+\gamma_{1} d_{t+1}^{*}+\phi d_{t}+\varepsilon_{t+1}
$$

Future leverage, $d_{t+1}$, is determined by target leverage, $d_{t+1}^{*}$, today's leverage, $d_{t}$, and an error term $\varepsilon_{t+1}$. The constant $\gamma_{0}$ term and coefficients $\gamma_{1}$ and $\phi$ are estimated. It is common in the literature to instrument out target leverage, $d_{t+1}^{*}$, with a regression of leverage on lagged firm characteristics (e.g., Flannery and Rangan, 2006; Kayhan and Titman, 2007; Lemmon et al., 2008; and Faulkender et al., 2012). Our target leverage measure is given by the fixed effects regression predictions, with the estimation in the real data presented in Appendix A. In the simulated data, the predictions are simply the firm's sample mean plus noise.

Table 1 Panel A presents actual and simulated estimates of the conventional partial adjustment model in Eq. (16), with a first order autoregressive model AR(1) in lagged leverage for comparison. Traditionally, the coefficient of interest is the fixed effects estimator, because it is consistent ${ }^{19}$ on lagged leverage, $\phi=(1-\lambda)$, which is one minus the SOA. ${ }^{20}$ There is very little change in fixed effects estimates of $\phi$, regardless of model or data. In the real data, the lagged coefficient cannot be an instructive test of trade-off theory if, in the absence of target leverage (i.e., in the AR(1) case), the same coefficient is obtained. In addition, a nearly identical coefficient on lagged leverage from the partial adjustment model can be generated with simulated data that is devoid of active rebalancing.

However, the fixed effects estimate on target leverage, $\gamma_{1}=\lambda$, is economically significant, as it is 0.429 in the actual data and zero in the simulated samples. ${ }^{21}$ This suggests that the coefficient on target leverage is potentially informative of capital structure adjustments, while the coefficient on the lagged leverage is simply mechanical and not helpful in detecting targeting behavior. Nonetheless, it is not clear yet how the coefficient on target leverage translates into any easy-to-gauge description of the targeting behavior, such as the likelihood of target oriented issuance, SOA, or the half-life of leverage deviations.

Panel A also reports the OLS estimates of the partial adjustment model, which are not usually consistent estimates in capital structure studies. However, with simulated data, we are able to examine the differences. The coefficient on target leverage is unaffected by choice of estimation method in the actual data. Target leverage is fixed effects based, and therefore contains the mean of each firm's leverage. This is why the naive simulated target is not significant when estimated with fixed effects, but is with OLS.

\footnotetext{
${ }^{18}$ In the real data, mean debt and mean equity have a low correlation, but firms that have low average tetained earnings will have high average net equity issuance - the cortelation is approximately negative one-half.

${ }^{19}$ Our fixed effect estimates are nearly identical to Chang and Dasgupta (2009) and Flannery and Rangan (2006). Consistency of coefficients in autoregressive panels with short time series has been a topic addressed in this literature. The size of the cross section cannot be used to prove a time series property. In dynamic panels estimates on the lagged endogenous variable are shown to be downward biased. This must also be true of our simulated data. Our illustration focuses on the informativeness of the partial adjustment model relative to its simulated counterpart and not the exact estimated coefficient.

${ }^{20}$ The traditional partial adjustment model is often rewritten as $d_{t+1}=\lambda d_{t+1}^{*}+(1-\lambda) d_{t}+\varepsilon_{t+1}$, a combination of target leverage and today's leverage where the SOA is $\lambda$.

21 Although the coefficient is significantly different, the $R^{2} / s$ of the empirical and the simulated partial adjustment models are nearly identical.
} 
Table 1

Pattial adjustment model vs. tatget financing model.

\begin{tabular}{|c|c|c|c|c|c|c|c|c|c|c|}
\hline & \multirow[t]{2}{*}{ Model } & & \multicolumn{4}{|c|}{ Empirical } & \multicolumn{4}{|c|}{ Simulated } \\
\hline & & & $\gamma_{1}$ & $\varnothing$ & $\Lambda$ & $R^{2}$ & $\gamma_{1}$ & $\varnothing$ & $\Lambda$ & $R^{2}$ \\
\hline \multirow[t]{2}{*}{$\mathrm{A} 1$} & \multirow[t]{2}{*}{$\begin{array}{l}\operatorname{AR}(1) \\
d_{t+1}=\gamma_{0}+\varnothing d_{t}+\varepsilon_{t+1}\end{array}$} & OLS & - & $\begin{array}{l}0.879^{* * *} \\
{[0.002]}\end{array}$ & 5.37 & 0.762 & & $\begin{array}{l}0.882^{* * *} \\
{[0.002]}\end{array}$ & 5.52 & 0.758 \\
\hline & & $\mathrm{FE}$ & - & $\begin{array}{l}0.685^{* * *} \\
{[0.004]}\end{array}$ & 1.83 & 0.816 & & $\begin{array}{l}0.640^{* * *} \\
{[0.003]}\end{array}$ & 1.55 & 0.828 \\
\hline \multirow[t]{2}{*}{$\mathrm{A} 2$} & \multirow[t]{2}{*}{$\begin{array}{l}\text { Partial adjustment } \\
d_{t+1}=\gamma_{0}+\gamma_{1} d_{t+1}+\varnothing d_{t}+\varepsilon_{t+1}\end{array}$} & OLS & $\begin{array}{l}0.432^{* * *} \\
{[0.005]}\end{array}$ & $\begin{array}{l}0.589^{* * *} \\
{[0.004]}\end{array}$ & 1.31 & 0.807 & $\begin{array}{l}0.217^{* * *} \\
{[0.002]}\end{array}$ & $\begin{array}{l}0.739^{* * *} \\
{[0.002]}\end{array}$ & 2.29 & 0.784 \\
\hline & & $\mathrm{FE}$ & $\begin{array}{l}0.429^{* * * *} \\
{[0.011]}\end{array}$ & $\begin{array}{l}0.654^{* * *} \\
{[0.004]}\end{array}$ & 1.63 & 0.820 & $\begin{array}{l}0.000 \\
{[0.002]}\end{array}$ & $\begin{array}{l}0.640^{* *} \\
{[0.003]}\end{array}$ & 1.55 & 0.828 \\
\hline
\end{tabular}

Panel B. Target financing model

\begin{tabular}{|c|c|c|c|c|c|c|c|c|c|c|c|c|}
\hline & \multirow[t]{2}{*}{ Model } & & \multicolumn{5}{|c|}{ Empirical } & \multicolumn{5}{|c|}{ Simulated } \\
\hline & & & $\gamma_{0}$ & $\theta$ & $\Lambda$ & $\Delta P$ & $R^{2}$ & $\gamma_{0}$ & $\theta$ & $\Lambda$ & $\Delta P$ & $R^{2}$ \\
\hline $\mathrm{T} 1$ & $\begin{array}{l}\text { Target financing } \\
\Delta_{1}=\gamma_{0}+\theta \Delta_{0}+\varepsilon\end{array}$ & $\begin{array}{l}\text { OLS } \\
{[0.0002]}\end{array}$ & $\begin{array}{l}0.003^{* * *} \\
{[0.022]}\end{array}$ & $5.364^{* * *}$ & 1.965 & $14.0 \%$ & $\begin{array}{l}0.296 \\
{[0.0002]}\end{array}$ & $\begin{array}{l}0.001^{* * *} \\
{[0.061]}\end{array}$ & $1.850^{* * *}$ & 3.358 & $5.3 \%$ & 0.022 \\
\hline
\end{tabular}

This table presents estimation and simulation results of an AR(1) model in lagged leverage, the conventional Partial adjustment model (Eq. (16)) of leverage (in Panel A), and the linearized target financing model (model T1, in Panel B). Models are tested with empirical data and 1000 simulated samples in which issuance decisions are random. Leverage is measured by the book debt to asset ratio. Leverage target, $d_{t+1}^{*}$, is based on firm characteristics estimated in a first-step regression in Appendix A. The target financing model (in Section 2) is given in a simple regression form (Eq. (T1)), $\Delta_{1}=\gamma_{0}+\theta \Delta_{0}+\varepsilon$, where $\Delta_{1}=d_{t+1}-d_{t}-k /(1+k)\left(d_{t+1}^{*}-d_{t}\right)$ is the left hand side, $\Delta_{0}=k /(1+k) \frac{k}{k \mid} d_{t+1}^{*}\left(1-d_{t+1}^{*}\right)\left(d_{t+1}^{*}-d_{t}\right)$ is the right-hand side, $\gamma_{0}$ is the intercept, $\varepsilon$ is the error term, $k$ is the financial deficit as described in the data section as the sum of net debt and net equity as a ratio of lagged assets. The pooled ous and fixed effects (FE) estimators are used for estimation of the AR(1) and the partial adjustment model, and oLS is used for target financing model. Point estimates and panel robust standard errors [in brackets] from the real data and simulated data are presented. $\Delta P$ is the predicted change in probability of issuance given the leverage is one standard deviation away from the target, and measures the average partial effect of the target financing model based on a linearized probability from a logistic distribution, $\mathrm{APE}=\theta \overline{\frac{k}{|k|} d_{t+1}^{*}\left(1-d_{t+1}^{*}\right)}$, evaluated at average target leverage multiplied by the unconditional standard deviation in leverage deviations (0.12). The sample consists of 140,731 firm years of U.S. Compustat data spanning 1970-2010. Panel A Half- Life $\Lambda$ is $\ln (0.5) / \ln (\varnothing)$. Panel B Half-Life $\Lambda$ (Eq. (12)) is calculated using estimated $\theta$ and sample average deficit and leverage $k=14.7$ and $d^{*}=0.437$, respectively. ${ }^{* * *}$ is significance at $1 \%$.

OLS estimates show that the coefficient on the lagged leverage is different in the real-world data $(\phi=0.589)$ than it is in the simulated data $(\phi=0.739)$. Lagged leverage is correlated with mean leverage, as firms with higher leverage have higher mean leverage, and target leverage contains mean leverage. Thus, the difference in OLS estimates of $\phi$ manifests the difference in correlation of firms' mean debt, equity, and retained earnings between simulated and empirical datasets, which is thrown out in the fixed effects estimation. While the correlation between mean debt and mean equity is small, firms that have low average retained earnings typically have high average net equity issuance - the correlation in the data is approximately negative one-half. This substantial negative correlation could be interpreted as evidence of deliberate capital structure choice in the way firms are initially set up, rather than a time series property, and is the reason simulations are set up to not have a connection in the means of the three financing variables. Thus, the OLS estimate of $\phi$, while not necessarily consistent, contains information on firm capital structure heterogeneity, but how this translates to a test of capital structure theory is not clear.

\subsection{Target financing models}

We present a direct comparison with the standard partial adjustment model, in Panel A of Table 1, to our linearized, financing-based partial adjustment model (T1) contained in Panel B. We present the (T1) estimates in the real and simulated data in both Panels. We leave a robustness check using discrete choice Logit and Probit models that do require an issuance indicator to Section 5.5. Both discrete dependent variable models and our linearized models provide statistically and economically significant evidence of targeting behavior.

The estimate of the target financing parameter, $\theta$, in the empirical data is 5.364 , which is many standard deviations above the simulated estimate, 1.850 . This indicates firms are likely to issue debt when under-levered and issue equity when overlevered. In other words, firms engage in active adjustments toward target leverage. The positive $\theta$ found in simulated data reveals either a small but significant effect from a mechanical relation between issuance decision and leverage deviation due to the inherent links among profitability, financial deficit, and security issuance, or a reflection of error in variables issues.

To evaluate the economic impact of targeting behavior, we translate $\theta$ into the predicted change in the probability of issuance, $\Delta P$, assessed at one standard deviation away from target leverage for the linear model, T1. $\Delta P$ is then the average partial effect (APE) of the probability model, APE $=\theta \overline{\frac{k}{|k|} d^{*}\left(1-d^{*}\right)}$ for T1, multiplied by the unconditional standard deviation of leverage deviations $(0.12)$. The target financing model, T1, reveals that the probability of issuance increases by $14 \%$ in response to 
a one-standard-deviation increase in leverage deviation, while the simulated increase is only $5.3 \%$. Thus, the non-random increase in the probability is almost 9 percent.

The speed of adjustment from the target financing model is much faster and the expected half-life of leverage deviation is much shorter than their counterparts under random financing. Using Eq. (9) and values for the average firm, which has a target leverage of 0.437 and a financial deficit 0.147 , the SOA from the empirical data $(\theta=5.364)$ is 0.297 , while in the random financing simulated sample $(\theta=1.850)$ it is 0.186 . The true SOA under the random financing model $(\theta=0)$ is 0.128 . The corresponding half-lives, $\Lambda$, given in Eq. (12) are 3.358 years in the random financing simulated sample and only 1.965 years with targeting. Thus, the SOA is $60 \%$ faster and the half-life is $42 \%$ shorter empirically than would be expected under random financing.

The R-squares in Table 1 also present a useful contrast between the conventional partial adjustment models and the target financing model. The conventional partial adjustment model produces essentially identical R-squares for the actual data and the simulated data. It tends to mistake the mechanical mean reversion for real rebalancing. The target financing model, however, has a fairly high R-square (0.296) in the actual data, but a very low R-square in the simulated data (0.022), showing its ability to distinguish active capital structure rebalancing from mechanical mean reversion.

\subsection{Model fit}

In this section, we examine the performance of the random financing model, the conventional partial adjustment model, and our target financing model in capturing the leverage dynamics in the real world. Table 2 presents results of specification tests. This table is generically structured to look at, first, how $X$ predicts $Y$, and second, how well the orthogonality condition $E[X \varepsilon]=0$ is satisfied with the three models. The $X$ variable is leverage deviation, $d_{t+1}^{*}-d_{t}$, in quintiles, and the $Y$ variable is actual leverage changes, $d_{t+1}-d_{t}$. The model errors, $\varepsilon$, are respectively from: (T1) with $\theta=0$ for the random financing model; (A2) for the conventional partial adjustment model with fixed effects estimation (Table $1, \varphi=0.654$ ); and (T1) with $\theta=5.364$ for the target financing model. We classify both raw leverage changes (in Panel A) and residual leverage changes from the three models (in Panels B, C, and D), i.e., model errors, into positive (greater than +1 percentage point), negative (lower than -1 percentage point), or zero (between -1 and +1 percentage point) categories. To examine the symmetry of adjustment, we also look at leverage changes and model errors through the lens of whether firms are in deficit or surplus. The percentages of observations in each leverage deviation quintile across positive, negative, or zero categories are tabulated.

Panel A shows leverage deviations are positively related to actual leverage changes, and this relation is monotonic. This indicates that our leverage target is well specified. In the full sample, positive leverage changes and negative ones are about equally likely ( $42 \%$ vs. $43 \%$ ). However, negative predicted deviations are more likely to be related to negative actual deviations, and likewise for positive deviations. For instance, strong positive predictions (quintile 5) result in positive changes in actual leverage $67 \%$ of the time, and strong negative leverage deviations (quintile 1) result in negative actual changes also $67 \%$ of the time. The pattern of leverage deviations and subsequent leverage changes loses some of its symmetry when conditioning on deficit or surplus, but remains monotonic. In the case of deficits, strong positive deviations are more likely to be associated with positive actual changes (quintile 5, 76\%) than strong negative deviations are associated with negative actual changes (quintile 1,58\%). Conditioned on surpluses, the opposite is true: strong negative deviations are much more likely to be associated with negative actual changes (quintile $1,81 \%$ ) than strong positive deviations are associated with positive actual changes (quintile 5, 34\%).

Panel $\mathrm{B}$ demonstrates that random financing fails to explain actual leverage changes. The random financing model errors are $e_{1}=d_{t+1}-d_{t}-k /(1+k)\left(d_{t+1}^{*}-d_{t}\right)$, where $k$ is the firm-specific financial deficit/surplus. The pattern found in Panel B is qualitatively very similar to the one found in Panel A. Leverage deviations are related in the same way to random financing adjusted changes as to actual leverage changes, thus the random financing model explains little of leverage dynamics.

Panel $C$ reveals that the conventional partial adjustment model overestimates the speed of adjustment, especially when firms face financial surpluses. The model adjusted leverage changes are defined by $e_{2}=d_{t+1}-d_{t}-\lambda\left(d_{t+1}^{*}-d_{t}\right)$, where $\lambda=0.346$, or one minus the estimated coefficient on lagged leverage under fixed effects (Table $1, \lambda=1-\varnothing$ ). Contrary to patterns in the above Panels, the partial adjustment model adjusted leverage changes exhibit a negative correlation with leverage deviations: the probability of a negative residual leverage change now monotonically increases from 40 percent to 51 percent, while that of a positive residual change near-monotonically decreases from 50 percent to 40 percent when the leverage deviation moves from the lowest quintile (quintile 1) to the highest quintile (quintile 5). This indicates that the partial adjustment model overstates the speed of adjustment, a result of failure to differentiate actual rebalancing from mechanical mean reversion. This overestimation problem is more pronounced when firms have financial surpluses: the probability of a negative residual leverage change now monotonically increases from 49 percent to 80 percent, while that of a positive residual change monotonically decreases from 38 percent to 16 percent when the leverage deviation moves from the lowest quintile to the highest quintile.

Panel D shows the target financing model is capable of capturing targeting while weeding out mechanical mean reversion. Target financing adjusted leverage changes are $e_{3}=\Delta_{1}-\gamma_{0}-\theta \Delta_{0}$, as defined in Eq. (T1), where $\Delta_{1}$ is the random financing adjusted leverage changes and $\gamma_{0}$ and $\theta$ take values of 0.003 and 5.364 respectively, as shown in Table 1 , Panel B. In the full sample, the likelihood of a negative residual leverage change declines from 57 percent when the target leverage deviation is in quintile 1 to 38 percent in quintile 5, and that of a positive leverage change increases from 34 percent to 45 percent. No 
Table 2

Model etrots in leverage deviation quintiles.

\begin{tabular}{|c|c|c|c|c|c|c|c|c|c|c|}
\hline \multicolumn{2}{|c|}{ Lev. deviation } & \multicolumn{3}{|c|}{ Full sample } & \multicolumn{3}{|c|}{ Deficit $(k>0,69 \%)$} & \multicolumn{3}{|c|}{ Surplus $(k<0,31 \%)$} \\
\hline Quintile & Median & neg & zero & pos & neg & zero & pos & neg & zero & pos \\
\hline \multicolumn{11}{|c|}{ A. Leverage changes } \\
\hline 1 & $-13.4 \%$ & 67 & 10 & 23 & 58 & 12 & 30 & 81 & 7 & 12 \\
\hline 2 & $-3.9 \%$ & 54 & 16 & 30 & 41 & 19 & 40 & 77 & 10 & 13 \\
\hline 3 & $1.1 \%$ & 38 & 20 & 42 & 26 & 22 & 52 & 66 & 15 & 20 \\
\hline 4 & $6.0 \%$ & 29 & 17 & 55 & 18 & 17 & 64 & 59 & 15 & 26 \\
\hline 5 & $14.6 \%$ & 20 & 13 & 67 & 11 & 12 & 76 & 49 & 17 & 34 \\
\hline All & & 42 & 15 & 43 & 29 & 17 & 54 & 69 & 12 & 19 \\
\hline \multicolumn{11}{|c|}{ B. Random financing model adjusted leverage changes } \\
\hline 1 & $-13.4 \%$ & 63 & 10 & 27 & 48 & 12 & 39 & 85 & 6 & 10 \\
\hline 2 & $-3.9 \%$ & 53 & 15 & 32 & 38 & 18 & 43 & 78 & 9 & 13 \\
\hline 3 & $1.1 \%$ & 38 & 20 & 42 & 27 & 22 & 51 & 65 & 15 & 20 \\
\hline 4 & $6.0 \%$ & 31 & 18 & 52 & 22 & 19 & 60 & 56 & 16 & 28 \\
\hline 5 & $14.6 \%$ & 24 & 15 & 61 & 18 & 15 & 67 & 44 & 18 & 39 \\
\hline All & & 42 & 16 & 43 & 30 & 17 & 53 & 69 & 12 & 20 \\
\hline \multicolumn{11}{|c|}{ C. Partial adjustment model adjusted leverage changes } \\
\hline 1 & $-13.4 \%$ & 40 & 11 & 50 & 33 & 9 & 58 & 49 & 13 & 38 \\
\hline 2 & $-3.9 \%$ & 42 & 17 & 41 & 29 & 18 & 52 & 65 & 15 & 20 \\
\hline 3 & $1.1 \%$ & 41 & 20 & 39 & 30 & 22 & 48 & 69 & 13 & 18 \\
\hline 4 & $6.0 \%$ & 46 & 15 & 39 & 36 & 17 & 47 & 74 & 9 & 17 \\
\hline 5 & $14.6 \%$ & 51 & 8 & 40 & 43 & 9 & 47 & 80 & 5 & 16 \\
\hline All & & 44 & 14 & 42 & 35 & 15 & 50 & 65 & 12 & 23 \\
\hline \multicolumn{11}{|c|}{ D. Target financial model adjusted leverage changes } \\
\hline 1 & $-13.4 \%$ & 57 & 9 & 34 & 40 & 11 & 49 & 81 & 7 & 13 \\
\hline 2 & $-3.9 \%$ & 52 & 15 & 33 & 37 & 18 & 45 & 78 & 9 & 13 \\
\hline 3 & $1.1 \%$ & 42 & 20 & 39 & 31 & 23 & 47 & 68 & 13 & 18 \\
\hline 4 & $6.0 \%$ & 37 & 19 & 44 & 29 & 20 & 51 & 61 & 14 & 25 \\
\hline 5 & $14.6 \%$ & 38 & 17 & 45 & 34 & 18 & 49 & 53 & 16 & 31 \\
\hline All & & 45 & 16 & 39 & 34 & 18 & 48 & 71 & 11 & 18 \\
\hline
\end{tabular}

This table presents tabulations of raw and model adjusted leverage changes by quintiles of leverage deviations from target levels. Zero change is defined as any small change between -1 and $+1 \%$. Deviations from target leverage, $d_{t+1}^{*}-d_{t}$, where $d_{t+1}^{*}$ is the fixed effects regression target presented in Table 1 , are classified into quintiles, with lowest deviations in quintile 1 and highest in quintile 5 . Raw leverage changes, $d_{t+1}-d_{t}$, are in Panel $A$. Panel B presents random financing adjusted changes, $\Delta_{1}=d_{t+1}-d_{t}-k /(1+k)\left(d_{t+1}^{*}-d_{t}\right)$, where $k$ is the financial deficit/surplus. Panel $C$ shows partial adjustment model adjusted changes: $d_{t+1}-d_{t}-\lambda\left(d_{t+1}^{*}-d_{t}\right)$, where $\lambda=0.346$ is taken from fixed effects estimates (1 $\left.-\varnothing\right)$ in Table 1 . Panel $\mathrm{D}$ shows target financing adjusted leverage changes, $\Delta_{1}-\gamma_{0}-\theta \Delta_{0}$, as defined in Eq. (T1), where $\Delta_{1}$ is the random financing adjusted leverage changes and $\Delta_{0}=k /(1+k) \frac{k}{k \mid} d_{t+1}\left(1-d_{t+1}^{*}\right)\left(d_{t+1}^{*}-d_{t}\right)$. The coefficients $\gamma_{0}=0.003$ and $\theta=5.364$ are taken from Table 1 . Results are presented in row percentages of negative, zero, and positive leverage changes in quintiles of leverage deviation along with the median leverage deviation of each quintile. The sample is also broken into firms with a financial deficit $(k>0)$ and those with a financial surplus $(k<0)$, where $k=n e i+n d i$ as defined in the data section. Percent of firm years in deficit and surplus is in parentheses.

pattern would be ideal, but it is much weaker than the raw data, indicating the model is capturing information on predicted leverage change. The model performs better under financial deficits than surpluses. Conditioned on financial deficits, the probability of a negative residual leverage change slides slowly and non-monotonically from 40 percent to 34 percent, and that of a positive residual change is essentially flat, regardless of the target leverage deviation. However, the pattern under financial surplus is qualitatively similar to the raw data in Panel A.

This analysis suggests that the target financial model performs better than either the random financing model or the conventional partial adjustment model in explaining leverage dynamics and fits adjustments given financial deficits better than those given surpluses. The asymmetry of model fit to deficits vs surpluses is addressed in Section 5.6.

\subsection{Target financing model sensitivity to deficit type}

In this section, we vary the definition of financial deficit and asset growth, the measure of target leverage, and the specification and estimation of the linear target financing model to investigate the robustness of our finding that the target financing model is superior in telling apart active capital structure rebalancing from mechanical mean reversion.

Table 3 presents estimates of the linear target financing model using alternative measures of financial deficit ( $k$ ) and asset growth $(g)$. Model T2 uses the firm's real financial deficit and asset growth. T3 uses the sample average financial deficit to measure both $k$ and $g$, as in Chang and Dasgupta (2009). Chang and Dasgupta (2009) justify $g=k$ by pointing out that the sample average of the change in retained earnings to assets is essentially zero. T4 uses the sum of a firm's average net debt financing plus average net equity financing to measure both $k$ and $g$.

The linear model estimates with different financial deficit definitions in Table 3 are qualitatively similar to the baseline linear model, T1, presented in Table 1. Estimates of the target financing parameter, $\theta$, are all positive and significantly 
Table 3

Target financing sensitivity to deficit type.

\begin{tabular}{|c|c|c|c|c|c|c|c|c|c|c|c|}
\hline & \multirow[t]{2}{*}{ Deficit type } & \multicolumn{5}{|c|}{ Empirical } & \multicolumn{5}{|c|}{ Simulated } \\
\hline & & $\gamma_{0}$ & $\theta$ & $\Lambda$ & $\Delta P$ & $R^{2}$ & $\gamma_{0}$ & $\theta$ & $\Lambda$ & $\Delta P$ & $R^{2}$ \\
\hline $\mathrm{T} 2$ & $\begin{array}{l}k=n d i+n e i \\
g=n d i+n e i+\Delta r e\end{array}$ & $\begin{array}{l}0.003^{* * *} \\
{[0.0002]}\end{array}$ & $\begin{array}{l}4.065^{* * *} \\
{[0.026]}\end{array}$ & 2.34 & $10.6 \%$ & 0.151 & $\begin{array}{l}0.001^{* * *} \\
{[0.0002]}\end{array}$ & $\begin{array}{l}1.214^{* * *} \\
{[0.072]}\end{array}$ & 3.81 & $3.0 \%$ & 0.010 \\
\hline T3 & $\begin{array}{l}k=\overline{n d i+n e i} \\
g=\overline{n d i+n e i}\end{array}$ & $\begin{array}{l}0.004^{* * *} \\
{[0.0002]}\end{array}$ & $\begin{array}{l}9.941^{* * *} \\
{[0.072]}\end{array}$ & 5.05 & $26.0 \%$ & 0.118 & $\begin{array}{l}0.002^{* * *} \\
{[0.0002]}\end{array}$ & $\begin{array}{l}2.474^{* * *} \\
{[0.078]}\end{array}$ & 3.00 & $6.5 \%$ & 0.019 \\
\hline $\mathrm{T} 4$ & $\begin{array}{l}k={\overline{n d i_{i}}}_{i}+\overline{n e i}_{i} \\
g=\overline{n d i}_{i}+\overline{n e i}_{i}\end{array}$ & $\begin{array}{l}0.004^{* * *} \\
{[0.0002]}\end{array}$ & $\begin{array}{l}5.879^{* * *} \\
{[0.048]}\end{array}$ & 1.84 & $15.4 \%$ & 0.096 & $\begin{array}{l}0.002^{* * *} \\
{[0.0002]}\end{array}$ & $\begin{array}{l}1.349^{* * *} \\
{[0.067]}\end{array}$ & 3.70 & $3.5 \%$ & 0.008 \\
\hline
\end{tabular}

This table presents the estimation of the linear target financing model with alternative measures of financial deficit and asset growth. The linear target financing model as described in Section 2 is given in a simple regression form (Eq. (T1)), $\Delta_{1}=\gamma_{0}+\theta \Delta_{0}+\varepsilon$, where $\Delta_{1}=d_{t+1}-d_{i}-k /(1+g)\left(d_{t+1}^{*}-d_{t}\right)$ is the left hand side, $\Delta_{0}=k /(1+g) \frac{k}{k} d_{t+1}^{*}\left(1-d_{t+1}^{*}\right)\left(d_{t+1}^{*}-d_{t}\right)$ is the right-hand side, $\gamma_{0}$ is the intercept, and $\varepsilon$ is the error term. $k$ is the financial deficit, measured by the real financial deficit (model T2), the sample average financial deficit (T3), and the sum of a firm's average net debt issues and average net equity issues (T4). $g$ is the asset growth, measured by the financial deficit plus changes in retained earnings (T2), the sample average financial deficit (T3), and the sum of a firm's average net debt issues and average net equity issues (T4). Point estimates and standard errors in brackets from the real data and simulated data are presented. $\Delta P$ is the predicted change in probability of issuance given the leverage is one standard deviation away from the target, and measures the average partial effect, $\mathrm{APE}=\theta \overline{\frac{k}{|k|} d_{t+1}^{*}\left(1-d_{t+1}^{*}\right)}$, evaluated at target leverage multiplied by the unconditional standard deviation in leverage deviations (0.12). The sample consists of 140,731 firm years of U.S. Compustat data spanning 1970-2010. Half-Life $\Lambda$ (Eq. (12)) is calculated using estimated $\theta / 5$, sample average deficit $(k=14.7 \%)$, and leverage $\left(d^{*}=0.437\right)$. ${ }^{* * *}$ marks statistical significance at the one percent level.

different from those in the simulated data. The probability of targeting-oriented issuance in response to a one-standarddeviation increase in leverage deviation, $\Delta P$, is anywhere from $7.6 \%$ to as much as $19.5 \%$, relative to simulated samples. In fact, $\Delta P$ is the largest when using the same definition as Chang and Dasgupta (2009).

The estimation of the target leverage is an issue of debate in the capital structure literature (e.g., Hovakimian and Li, 2012). To verify that our findings are not attributable to the proxy of the target leverage, we employ two alternative measures of the target: (1) the historic median leverage of firms in the same 4-digit SIC industry, and (2) the predicted value of the dynamic panel model of capital structure using the doubly censored fractional dependent variable estimator (dubbed DPF estimator) proposed by Elsas and Florysiak (2015). The dynamic panel model is essentially the partial adjustment model in Eq. (16) with $d^{*}$ replaced by the same set of firm characteristics as in our baseline target leverage model. This model is often used to estimate the capital structure SOA but also used to estimate the target leverage (e.g., Faulkender et al., 2012). Simulation work of Dang et al. (2015) shows that the DPF estimator produces estimates with the greatest accuracy and efficiency. In addition, the heterogeneity of target leverage and financial deficit across firms indicates there may be firm-specific observable and/or unobservable variables correlated with $\Delta_{1}$ in the linear model T1 that are not explicitly netted out through its initial specification, which is not textbook fixed effects. To address this issue, we bring in firm characteristics to the right-hand side of T1 and estimate it with OLS, as well as estimate T1 using the fixed effects approach. ${ }^{22}$

Table 4 presents the estimation results using alternative target leverages, model specifications, and estimators in both the real data and the simulated data. To save space, standard errors are not reported. The first row is the baseline results reported in Table 1. In all rows, we observe the same pattern: the estimates of $\theta$ are much greater in the real data than in the simulated data. Thus, our main findings do not change qualitatively regardless of the proxy of target leverage, the model specification, or the estimator.

\subsection{Discrete choice models}

For a further robustness check, we estimate discrete dependent variable versions of our target financing model, which do require an issuance indicator to estimate the target financing parameter $\theta$. There are three discrete choice models examined: the Logit model with a common issuance probability (P1), the Logit model with heterogeneous issuance probability (P2), and a fixed effects Probit model (P3).

A precondition for estimating the discrete dependent variable target financing models is to define the binary response variable, dissue, standing for debt issuance. Ideally, it is equal to one if a firm issues/retires debt to meet its financial deficit/surplus without resorting to equity, or zero if it issues/repurchases equity without changing its debt as required by the leverage updating Eq. (1).

Recognizing the complexities of financing decisions, debt issuance needs to be defined in a way that minimizes measurement error. We define debt issuance as one when net debt issuance ( $n d i$ ) is greater than net equity issuance (nei), and zero otherwise. ${ }^{23}$ According to this definition, firms issue debt 53.7 percent of the time, and firms issue equity 46.3 percent of the time to meet their external financing needs. (See Appendix B, Table B1, Panel A.) Further examinations indicate that the

\footnotetext{
${ }^{22}$ We thank an anonymous referee for valuable suggestions regarding alternative target proxies, model specification, and estimation.

23 Debt issuance = 1 can apply to any of the following scenarios: debt issue accompanied by less or no equity issue, or equity repurchase; zero debt issue by equity repurchase; debt retirement by more equity repurchase. As a robustness check, we define debt issuance = 1 when a firm's leverage increases as the result of issuance, and 0 otherwise. The estimation results of models P1-P3 are qualitatively similar to those based on the baseline definition.
} 
Table 4

Target financing model: Alternative target estimates, specifications, and estimators.

\begin{tabular}{|c|c|c|c|c|c|c|c|c|c|c|}
\hline \multirow[t]{2}{*}{ Target type } & \multirow{2}{*}{$\begin{array}{l}\text { Include firm } \\
\text { characteristics }\end{array}$} & \multirow[t]{2}{*}{ Method } & \multicolumn{4}{|c|}{ Empirical } & \multicolumn{4}{|c|}{ Simulated } \\
\hline & & & $\gamma_{0}$ & $\theta$ & $\Lambda$ & $\Delta \mathrm{P}$ & $\gamma_{0}$ & $\theta$ & $\Lambda$ & $\Delta \mathrm{P}$ \\
\hline \multirow{3}{*}{$\begin{array}{l}\text { Fixed effects } \\
\text { predicted value }\end{array}$} & NO & OLS & $0.003^{* * A}$ & $5.364^{\text {*a** }}$ & 1.96 & $14.0 \%$ & $0.001^{\text {*:** }}$ & $1.850^{* * *}$ & 3.36 & $4.8 \%$ \\
\hline & YES & OLS & $0.003^{* * 1}$ & $4.787^{*: * *}$ & 2.12 & $12.5 \%$ & $0.039^{* * * *}$ & $0.587^{* * *}$ & 4.37 & $1.5 \%$ \\
\hline & NO & $\mathrm{FE}$ & & $5.209^{* * * *}$ & 2.00 & $13.6 \%$ & & $1.500^{* * *}$ & 3.59 & $3.9 \%$ \\
\hline \multirow{3}{*}{$\begin{array}{l}\text { Historic industry } \\
\text { median }\end{array}$} & NO & OLS & $0.004^{* * *}$ & $2.131^{* * *}$ & 3.19 & $13.7 \%$ & $0.022^{* * *}$ & $-0.508^{* * *}$ & 5.83 & $-3.3 \%$ \\
\hline & YES & OLS & $0.014^{* * *}$ & $2.140^{* * *}$ & 3.18 & $13.8 \%$ & $0.045^{* * * *}$ & $0.586^{* * *}$ & 4.37 & $3.8 \%$ \\
\hline & NO & $\mathrm{FE}$ & & $3.510^{* * *}$ & 2.54 & $22.6 \%$ & & $1.364^{* * *}$ & 3.69 & $8.8 \%$ \\
\hline \multirow{3}{*}{$\begin{array}{l}\text { DPF predicted } \\
\text { value }\end{array}$} & NO & OLS & $0.003^{x * x}$ & $2.622^{* * * *}$ & 2.93 & $12.2 \%$ & $0.021^{* * *}$ & $-0.749^{* * *}$ & 6.28 & $-3.5 \%$ \\
\hline & YES & OLS & $0.012^{* * *}$ & $2.626^{* 2 * *}$ & 2.93 & $12.2 \%$ & $0.050^{* 2 *}$ & $0.459^{* * *}$ & 4.50 & $2.1 \%$ \\
\hline & NO & $\mathrm{FE}$ & & $4.336^{20 * *}$ & 2.25 & $20.2 \%$ & & $1.555^{* * *}$ & 3.55 & $7.2 \%$ \\
\hline
\end{tabular}

This table presents the estimation of the linear target financing model with alternative measures of target estimates, specifications, and estimators. The linear target financing model as described in the modeling section is given in a simple regression form, $\Delta_{1}=\gamma_{0}+\theta \Delta_{0}+\varepsilon$, where $\Delta_{1}=d_{t+1}-d_{t}-k /(1+g)\left(d_{t+1}-d_{t}\right)$ is the left hand side, $\Delta_{0}=k /(1+g) \frac{k}{|k|} d_{t+1}^{t}\left(1-d_{t+1}\right)\left(d_{t+1}-d_{t}\right)$ is the right-hand side, $\gamma_{0}$ is the intercept, and $\varepsilon$ is the error term. Target 1 is the baseline measure of target leverage based on fixed effects (FE) estimation as reported in Appendix A. Target 2 is the 4-digit SIC industry historic median leverage. Target 3 is the predicted value of the dynamic partial adjustment model using the doubly censored fractional dependent variable estimator (DPF estimator). An alternative specification includes lagged firm characteristics on the right-hand side and is estimated using OLS. The original model is also estimated using the fixed effects approach. Point estimates from the real data and simulated data are presented and standard errors suppressed. $\triangle P$ is the predicted change in probability of issuance given the leverage is one standard deviation away from the target and measures the average partial effect, $\mathrm{APE}=\theta \overline{\frac{k}{k \mid} d_{t+1}\left(1-d_{t+1}^{*}\right)}$, evaluated at target leverage multiplied by the unconditional standard deviation in leverage deviations. The sample consists of 140,731 firm years of U.S. Compustat data spanning 1970-2010. ${ }^{* *}$ marks statistical significance at the one percent level. Half-Life $A$ (Eq. (12)) is calculated using estimated $\theta / s$, sample average deficit $(k=14.7 \%)$, and leverage $\left(d^{*}=0.437\right)$.

indicator variable is defined well. When the indicator variable is 1 and the firm is supposed to be issuing debt, debt is actually issued 94.6 percent of the time. When the indicator variable is 0 , and the firm is supposed to be issuing equity, equity is issued 76.3 percent of the time. How are issuance decisions related to leverage changes? Appendix B, Table B1, Panel C shows that when our debt issuance indicator equals one, it is associated with a leverage increase 81.8 percent of the time and when our debt issuance indicator equals zero, it is associated with a leverage decrease 75.1 percent of the time.

Appendix B, Table B2 reports empirical and simulated estimation results of the discrete choice target financing models. These results are quite similar, but more muted, to those of the target financing model in Table 1, confirming evidence of targeting behavior. The $\theta$ estimates range from 2.7 to 4 and are a number of standard errors away from their nontargeting simulated values. However, the predicted changes in probability of issuance given that leverage is one standard deviation away from target leverage, $\Delta P$, are almost as high. This change in probability is $14.1 \%$ in the linearized model (Table 1) and ranges from $10.5 \%$ to $11.3 \%$ when estimated in discrete choice models. We speculate that the more muted estimates of the target financing parameter are a consequence of having to choose a specific binary issuance measure.

\subsection{Asymmetric adjustment}

Asymmetric adjustment to deficit versus surplus as evidenced in Table 2 is documented in the literature (e.g., Faulkender et al., 2012). Adjustment under surplus is less costly than under deficits, and firms usually will use the surplus to retire debt (CD, 2009). Table 2 documents that deficits (69\%) are much more likely than surpluses (31\%).

To allow for asymmetric adjustment in the target financing model we make the target financing parameter, $\theta$, a simple function of deficit/surplus by including an indicator of whether a deficit $(k \geqslant 0)$ or a surplus $(k<0)$ is recorded for each firm year. The modified model (Eq. (T1)) is then,

$$
\Delta_{1}=\gamma_{0}+\gamma^{+}(k>0)+\left[(k>0) \theta^{+}+(k \leqslant 0) \theta^{-}\right] \Delta_{0}+\varepsilon
$$

where $\Delta_{0}$ and $\Delta_{1}$ are defined as before and $\theta^{+}$and $\theta^{-}$are two target financing parameters, respectively for the financial deficit and surplus situations. $\gamma_{0}$ is the intercept and $\gamma^{+}$captures the change in intercept given financial deficits.

Modelling firms with persistent and certain financial surpluses presents logical and modeling difficulties. A firm that has no need for external financing will have a target debt ratio of zero. In the random financing model and our targeting financing model as well, the persistent retirement of debt requires assets to be sold and the firm eventually ceases to exist. ${ }^{24} \mathrm{~A}$ unit root problem presents itself in Eq. (6) when $k<0$, with SOAs and half-lives being negative. To address this feasibility issue, we compare estimates and half-lives of our unrestricted sample to those in a sample where each firm's average random financing

\footnotetext{
${ }^{24}$ Allowing positive retained earnings does not solve the persistent surplus issue. We can show that retaining enough earnings will allow assets to grow, yet the leverage will decline and the stationary debt ratio is negative, in either the random financing or our targeting financing model.
} 
Table 5

Asymmetric target financing model.

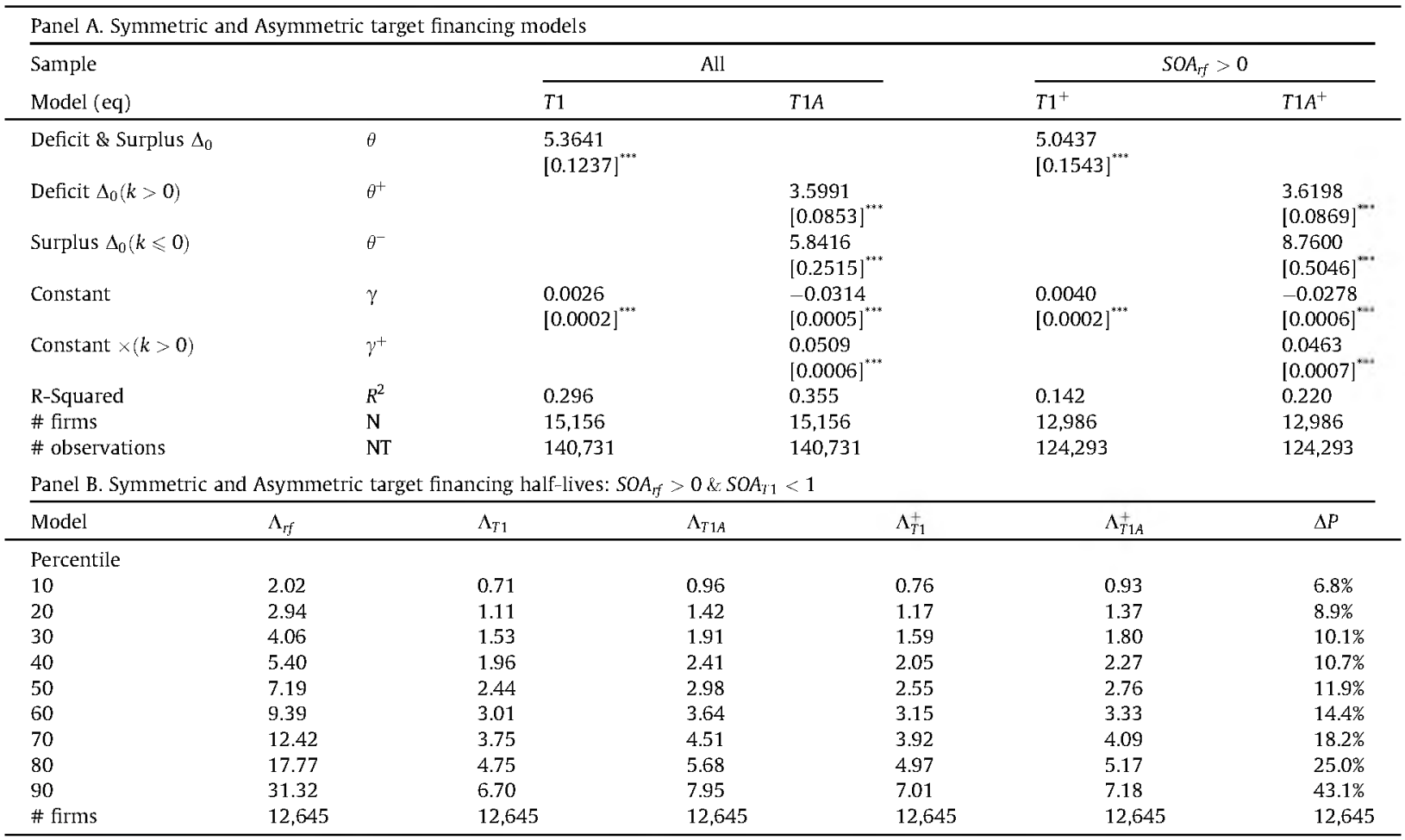

This table presents estimation of the linearized target financing model (Eq. $T 1$ ) and a target financing model allowing for asymmetry of adjustment to financial deficits $(k>0)$ and financial surplus $(k \leqslant 0)$ as in eq. $T 1 A: \Delta_{1}=\gamma+\gamma^{+}(k>0)+\left[(k>0) \theta^{+}+(k \leqslant 0) \theta^{-}\right] \Delta_{0}+\varepsilon$, where $\Delta_{1}$ and $\Delta_{0}$ are the same as defined in Table 1 Panel $\mathrm{B}, \theta^{+}$and $\theta^{+}$are the estimated financing parameters in deficit or surplus, and $\gamma$ and $\gamma^{+}$are the intercept and change in intercept given financial deficits. The slope and intercept change depend on deficit or surplus for a particular firm year. $k$ is the financial deficit as described in the data section as the sum of net debt and net equity as a ratio of lagged assets. OlS is used for the target financing model. $T 1^{+}$and $T 1 A^{+}$are the same two models above estimated in a sample where the random financing SOA for each firm measured as the time series average, $S O A_{r j}=\overline{\mathrm{k} /(1+\mathrm{k})}$, is positive. Point estimates are reported, standard errors are in brackets, and statistical significance at the one percent level is marked by ${ }^{* * *}$. Panel B presents Half-Life $\Lambda$ (Eq. (12)) calculated using the firm level time series average SOAs under each of the four models in Panel A. To calculate a feasible half-life, both $S O A_{r f}>0$ and $S O A_{r f}<1$ are required. Marginal effect, $\triangle P$, is the firm level time series average of the model $\Lambda_{11 A}^{+}$solved by using firm average SOAs and Eq. (13c) times one standard deviation of leverage deviation from target.

SOA, $\overline{k /(1+k)}$, is required to be positive. The distribution of half-lives under the baseline (symmetric) and asymmetric target financing models is also examined.

Table 5, Panel A presents the estimation results of the symmetric and asymmetric target financing models, with and without the feasibility condition. As expected, adjustment is more likely under surplus. The first column replicates the baseline target financing results in Table 1 (model $T 1$ ). In the asymmetric target financing model (model $T 1 A$ ), the target financing parameter under surplus $\left(\theta^{-}=5.84\right)$ is 61 percent higher than that under deficit $\left(\theta^{+}=3.59\right)$. The feasibility condition reduces the number of firms by $14.3 \%$. The magnitude of $\theta$ is slightly lower at 5.04 under the T1 model in the restricted sample (model $\left.T 1^{+}\right)$and the sensitivity to adjustment under surplus $\left(\theta^{-}=8.76\right.$ ) now more than doubles that under deficit, which remains nearly the same as in the unrestricted sample $\left(\theta^{+}=3.62\right.$ ), as shown in the last column (model $T 1 A^{+}$).

Table 5, Panel B takes the estimates from Panel A and considers their effects on the distribution of half-lives. For half-life feasibility, we require average random financing $S O A$ to be positive $\left(S O A_{r f}>0\right)$ and the $S O A$ of the target finance model to be less than one $\left(S O A_{T 1}<1\right)$. This added requirement reduces the number of firms by another 341 . The firm half-life (Eq. (12)) is calculated using a time series average of firm SOAs (Eq. (13c)).

The heterogeneity of half-lives is pronounced in the data. Random financing half-lives range from 2 to over 31 years. For target financing models, half-lives are substantially shorter, ranging from just under a year at the 10 th percentile to just under 8 years at the 90 th percentile, across target models and samples. Notable is that half-life distributions are very similar across symmetric and asymmetric target financing models, with the asymmetric models having slightly longer ones. ${ }^{25}$ The median half-life

\footnotetext{
${ }^{25}$ Even though the probability of repurchase is higher than issuance in the asymmetric model, deficits have a lower sensitivity than in the constant slope
} model and firms face deficits most of the time. 
Table 6

Targeting vs. pecking order.

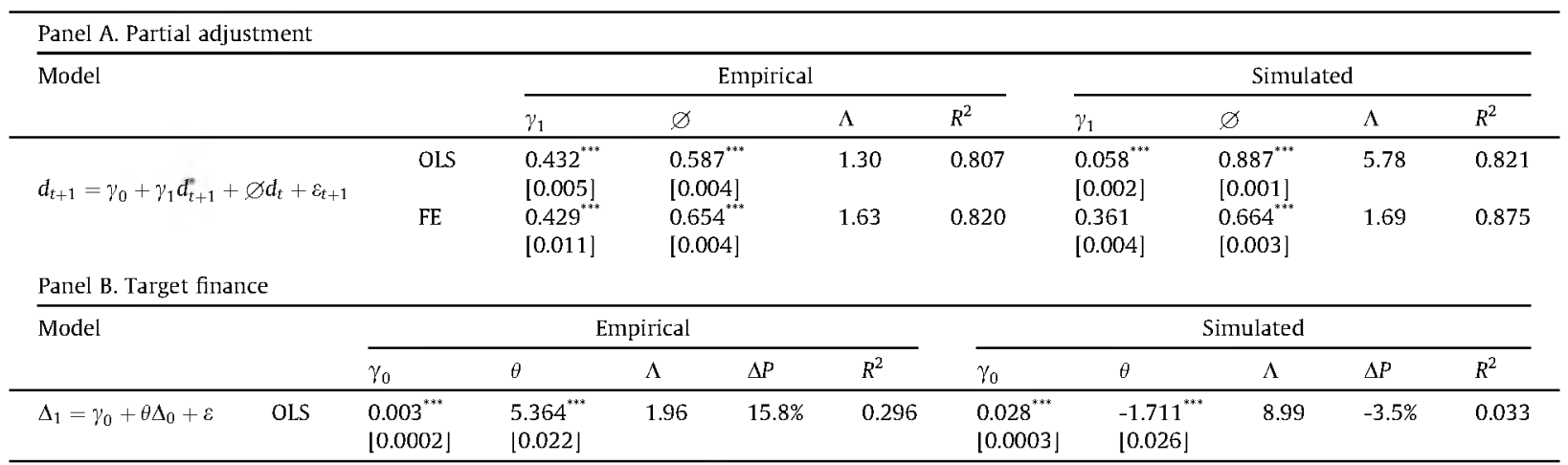

This table presents the estimation of the partial adjustment model of leverage ratio (in Panel A) and the linearized target financing model (model T1, in Panel B) in the empirical data and 1000 simulated samples based on pecking order financing strategy. Leverage is measured by the book debt to asset ratio. leverage target, $d_{t+1}^{*}$, is based on firm characteristics estimated in a first-step regression in Appendix A. The target financing model is given in a simple regression form $\Delta_{1}=\gamma_{0}+\theta \Delta_{0}+\varepsilon$, where $\Delta_{1}=d_{t+1}-d_{t}-k /(1+k)\left(d_{t+1}^{*}-d_{t}\right)$ is the left-hand side, $\Delta_{0}=k /(1+k) \frac{k}{|k|} d_{t+1}^{*}\left(1-d_{t+1}^{*}\right)\left(d_{t+1}^{*}-d_{t}\right)$ is the righthand side, $\gamma_{0}$ is the intercept, $\varepsilon$ is the error term, and $k$ is the financial deficit as described in the data section as the sum of net debt and net equity as a ratio of lagged assets. The pooled OLS and fixed effects (FE) estimators are used for estimation of the partial adjustment model and ols is used for the target financing model. Point estimates and standard errors in brackets from the real data and simulated data are presented. $\Delta P$ is the predicted change in probability of issuance given the leverage is one standard deviation away from the target, and measures the average partial effect of the target financing model, APE $=\theta_{\frac{k}{k \mid} d_{t+1}^{*}\left(1-d_{t+1}\right)}$, evaluated as average target leverage multiplied by the unconditional standard deviation in leverage deviations (0.12). The sample consists of 140,731 firm years of U.S. Compustat data spanning 1970-2010." marks statistical significance at the one percent level. Panel A HalfLife $\Lambda$ is $\ln (0.5) / \ln (\varnothing)$. Panel B Half-Life $\Lambda$ (Eq. (12)) is calculated using estimated $\theta$, sample average deficit $k=14.7$, and leverage $d^{*}=0.437$.

is 7.19 years with random financing and is between 2.44 and 2.98 years under target financing, representing a reduction of $60-66$ percent, or nearly 5 years. This again highlights the ability of our target financing model to tell apart mechanical mean reversion and active rebalancing. In the asymmetric target financing model, the median change in the probability of issuance, $\Delta P$, is $11.9 \%$, evaluated at one standard deviation from target is nearly the same as reported in Table 1 (14.1\%).

\subsection{Pecking order}

Myers and Majluf (1984) posit that adverse selection costs make external financing less desirable than internal funds, with external equity financing being the least desirable of all. Thus, firms should use internal funds first before borrowing, and equity financing is the last resort. Shyam-sunder and Myers (1999) show that simulation based on pecking order financing generates patterns of leverage ratios that mean revert. The conventional partial adjustment model cannot tell targeting from pecking order financing, even as pecking order financing responds solely to financial deficits and not to any target or leverage deviation. Allowing for leverage changes to depend on leverage deviation, our target financing model has the potential to distinguish targeting behavior from pecking order behavior.

We follow Shyam-sunder and Myers (1999) to generate simulated debt ratios that follow the pecking order of financing. Specifically, a firm in our sample is assumed to issue debt if the deficit is positive and retire debt if it is negative. In this simulated sample, we re-estimate the conventional partial adjustment model, as well as the target financing models, and compare them with the estimates in real-world data. Table 6 presents the comparison. The partial adjustment model cannot distinguish targeting from pecking order, as the coefficient on lagged leverage is essentially the same in the data and the simulated pecking order sample, verifying the Shyam-sunder and Myers (1999) results. In contrast, when the target financing models are employed, we find the target financing parameter, $\theta$, is much larger in the real-world data than in the simulated pecking order data. Thus, our target financing model is powerful enough to tell apart targeting behavior from random financing as well as pecking order financing.

\section{Conclusion}

We extend the critique of the conventional capital structure partial adjustment model to show, analytically and in simulations, that the generally cited "speed of adjustment" estimate reflects the autocorrelation in leverage that mechanically develops in the process of leverage evolution and is not informative of financing strategy. It cannot differentiate targeting behavior from random financing or pecking order financing. Specifically, in the conventional partial adjustment framework, estimates of coefficients on lagged leverage are about the same, whether they are estimated using real-world data, simulated data where issuance decisions are completely random, or following the pecking order strategy. To the extent that the auto- 
correlation of leverage is viewed as one minus the speed of adjustment, the financing information is lost in the translation from issuance decisions to leverage evolution.

To retrieve the lost financing information, we propose target financing models to link the choice of debt or equity issuance with the leverage deviation from target. A firm would be more likely to issue (retire) debt or repurchase (issue) stock when under-levered (over-levered) if it tries to eliminate the leverage deviation; otherwise we will not observe any significant association between leverage deviation and issuance decisions. Nesting targeting and alternative financing strategies, the models enable us to separate the effect of targeting behavior on leverage evolution from mechanical mean reversion of the leverage ratio. The linearized partial adjustment representation of the target financing model gives the SOA explicitly as the product of the effect of targeting behavior and the effect of random financing.

We describe leverage evolution using the conventional partial adjustment model and our target financing model, in realworld data as well as in simulated data based on alternative financing strategies. The conventional partial adjustment model has similar estimates of the coefficient of lagged leverage in both the real-world data and the simulated data, failing to distinguish targeting behavior from random financing. In contrast, our target financing models yield significantly larger estimates of the target financing, and the average partial effect of leverage deviation on issuance decisions is far more pronounced in real-world data than in simulated data. Overall, expected SOA from active rebalancing (30\%) more than doubles what is expected from mechanical mean reversion alone (13\%). Comparisons of estimates between the real-world data and the simulated pecking-order data also generate similar results. Thus, our target financing model, capable of distinguishing targeting behavior from alternative financing strategies, finds that firms indeed engage in issuance activities aimed at narrowing leverage deviations, consistent with the generalized tradeoff theory of capital structure.

\section{Appendix A. Target formation}

The following table presents the fixed effects (that includes time effects) estimation of the target leverage model. The coefficients on predicting variables, including a vector of firm characteristics and the industry median leverage, and the corresponding standard errors [in brackets] are reported on the left side of the Table. ${ }_{* * *}$ marks statistical significance at the $1 \%$ level. The descriptive summary of the leverage measure $\left(l e v_{t+1}\right)$ and the predicting variables are shown on the right. The sample consists of 140,731 firm years of U.S. Compustat data spanning 1970-2010. Sample specifics including the construction of the leverage measure, firm characteristics, and industry median leverage are in the Data section.

\section{Table A1}

Target estimation.

\begin{tabular}{|c|c|c|c|c|}
\hline$N=140,731$ & Estimation & Mean & Median & Std \\
\hline$l e v_{t+1}$ & & 0.437 & 0.435 & 0.203 \\
\hline$m t b_{t}$ & $\begin{array}{l}-0.006^{\text {***** }} \\
{[0.001]}\end{array}$ & 1.755 & 1.259 & 1.510 \\
\hline profit $_{t}$ & $\begin{array}{l}-0.237^{* * * *} \\
{[0.007]}\end{array}$ & 0.111 & 0.129 & 0.148 \\
\hline size $_{\mathbf{t}}$ & $\begin{array}{l}0.008^{\text {***** }} \\
{[0.002]}\end{array}$ & 5.255 & 5.064 & 1.953 \\
\hline tangi $i_{\mathrm{t}}$ & $\begin{array}{l}0.083^{* * * *} \\
{[0.010]}\end{array}$ & 0.313 & 0.263 & 0.226 \\
\hline$r d_{\mathrm{t}}$ & $\begin{array}{l}-0.011^{\text {**** }} \\
{[0.001]}\end{array}$ & 0.126 & 0.000 & 0.783 \\
\hline$r d d_{\mathrm{t}}$ & $\begin{array}{l}0.000 \\
{[0.003]}\end{array}$ & 0.451 & 0.000 & 0.498 \\
\hline depre $_{\mathrm{t}}$ & $\begin{array}{l}0.457^{* * * *} \\
{[0.040]}\end{array}$ & 0.045 & 0.038 & 0.031 \\
\hline indle $v_{\mathrm{t}}$ & $\begin{array}{l}0.308^{* * * * *} \\
{[0.035]}\end{array}$ & 0.423 & 0.420 & 0.086 \\
\hline Pooled $R^{2}$ & $19.8 \%$ & & & \\
\hline Within $R^{2}$ & $8.0 \%$ & & & \\
\hline$\%$ obs trimmed & $0.04 \%$ & & & \\
\hline Overall $R^{2}$ & $68.7 \%$ & & & \\
\hline
\end{tabular}




\section{Appendix B. Discrete dependent variable target financing models}

For robustness we estimate discrete dependent variable variants of our target financing model which do require an issuance indicator. There are three discrete choice models examined: the Logit model with a common issuance probability (P1), the Logit model with heterogeneous issuance probability (P2), and a fixed effects Probit model (P3).

The first empirical model is a Logit with common probability of issuance, or a pooled Logit specification with predicated probability:

$$
P_{C}\left(I_{d} \mid d_{t+1}^{*}, d_{\mathrm{t}}\right)=1 /\left[1+e^{-\left(\alpha+\theta\left(d_{t+1}^{*}-d_{\mathrm{t}}\right)\right)}\right]
$$

where the issuance indicator $I_{d}$ is equal to one when net issuance of debt exceeds net issuance of equity, $I_{d}(n d i>n d e)=1$, and zero otherwise. Target leverage for time $t+1, d_{t+1}^{*}$, is the fixed effects regression based target presented in Appendix A, and leverage deviation is defined as deviation of lagged leverage from target leverage, $\left(d_{t+1}^{*}-d_{t}\right)$. The coefficient $\theta$ measures the sensitivity of debt issuance to leverage deviations and is able to detect targeting behavior.

In the second specification, the restriction on the probability of issuance is relaxed to allow for firm-specific probability of issuance (i.e., heterogeneous target leverage), with the added term $\ln \left(\frac{d_{t+1}^{t}}{1-d_{t+1}^{t}}\right)$. Now, the predicated probability becomes:

$$
P_{H}\left(I_{d} \mid d_{t+1}^{*}, d_{t}\right)=1 /\left[1+\exp \left(-\left(\alpha+\delta \ln \left(\frac{d_{t+1}^{*}}{1-d_{t+1}^{*}}\right)+\theta\left(d_{t+1}^{*}-d_{t}\right)\right)\right)\right]
$$

where $\delta$ is the logistic scale parameter.

The third specification is a Probit estimator that also allows for firm-specific effects, captured by heterogeneous intercepts, $\alpha_{i}$, and a common coefficient parameter on leverage deviations,

$$
P_{F}\left(I_{d} \mid d_{t+1}^{*}, d_{t}, \alpha_{i}\right)=\Phi\left(\alpha_{i}+\theta\left(d_{t+1}^{*}-d_{t}\right)\right) .
$$

Table B1

Financing decisions.

\begin{tabular}{|c|c|c|c|}
\hline & Mean & Median & Std \\
\hline Asset growth & 0.147 & 0.080 & 0.346 \\
\hline Change in retained earnings/assets & 0.007 & 0.031 & 0.160 \\
\hline \multirow[t]{2}{*}{ Financial deficit/assets } & 0.140 & 0.050 & 0.334 \\
\hline & $>0$ & $>5 \%$ & $<-5 \%$ \\
\hline Financial deficit/assets & $69.1 \%$ & $50.1 \%$ & $15.5 \%$ \\
\hline Fraction financial deficit satisfied by debt & 0.734 & 0.872 & 3.264 \\
\hline \multicolumn{4}{|c|}{ Panel $C$. Leverage changes and net issuance indicator } \\
\hline & \multicolumn{2}{|l|}{$n d i<n e i(46.3 \%)$} & $n d i>n e i(53.7 \%)$ \\
\hline$(50.7 \%) \Delta l e v_{t}>0$ & \multirow{2}{*}{\multicolumn{2}{|c|}{$\begin{array}{l}18.2 \% \\
75.1 \%\end{array}$}} & $81.8 \%$ \\
\hline$(49.3 \%) \Delta l e v_{t}<0$ & & & $24.9 \%$ \\
\hline
\end{tabular}

\begin{tabular}{llllllll}
\hline \multicolumn{2}{l}{ Panel A. Financing decisions and net issuance indicator } & $n d i<$ nei (46.3\%) & $n d i>$ nei $(53.7 \%)$ & & \multicolumn{3}{c}{ Equity decision } \\
\hline Debt decision & & & Repurchase & No action & Issue & Total \\
& Repay & $71.0 \%$ & $4.9 \%$ & $9.6 \%$ & $4.0 \%$ & $21.9 \%$ & $35.4 \%$ \\
& No action & $1.4 \%$ & $0.6 \%$ & $0.3 \%$ & $0.1 \%$ & $0.6 \%$ & $1.0 \%$ \\
& Issue & $27.6 \%$ & $94.6 \%$ & $14.8 \%$ & $5.1 \%$ & $43.7 \%$ & $63.6 \%$ \\
& Total & $100 \%$ & $100 \%$ & $24.6 \%$ & $9.2 \%$ & $66.2 \%$ & $100.0 \%$ \\
Equity decision & Repurchase & $15.0 \%$ & $32.9 \%$ & & & & \\
& No action & $8.7 \%$ & $9.6 \%$ & & & & \\
& Issue & $76.3 \%$ & $57.5 \%$ & & & &
\end{tabular}

Panel B. Financial deficit

This table shows how the debt issuance indicator, dissue, is associated with debt and equity issuance/repurchase decisions (Panel A), properties of financial deficit (Panel B), and leverage changes (Panel C). The indicator dissue $=1$ if ndi $>$ nei and 0 otherwise, where nei and ndi represent net debt and equity issues, respectively, as a ratio to total assets and take negative values when debt (equity) is repaid (repurchased). No action is defined as net equity or debt issues within the $(-0.1 \%, 0.1 \%)$ range. The sample consists of 140,731 firm years of U.S. Compustat data spanning $1970-2010$ 
Discrete choice models.

\begin{tabular}{|c|c|c|c|c|c|c|c|c|c|c|c|}
\hline & \multirow[t]{2}{*}{ Model } & \multicolumn{5}{|c|}{ Empirical } & \multicolumn{5}{|c|}{ Simulated } \\
\hline & & $\delta$ & $\theta$ & $\Lambda$ & $\Delta P$ & $R^{2}$ & $\delta$ & $\theta$ & $\Lambda$ & $\Delta P$ & $R^{2}$ \\
\hline P1. & $\begin{array}{l}\text { Common issuance probability: } \\
P_{C}\left(I_{d} \mid d_{t+1}^{*}, d_{t}\right)\end{array}$ & - & $\begin{array}{l}3.998^{* * *} \\
{[0.065]}\end{array}$ & 2.36 & $11.3 \%$ & 0.050 & - & $\begin{array}{l}1.675^{* * * *} \\
{[0.031]}\end{array}$ & 3.47 & $4.9 \%$ & 0.022 \\
\hline P2. & $\begin{array}{l}\text { Heterogeneous issuance } \\
\text { probability: }\end{array}$ & $3.998^{\text {*** }}$ & $3.965^{* * *}$ & 2.37 & $11.1 \%$ & 0.064 & $0.161^{* * *}$ & $1.143^{* * * *}$ & 3.86 & $3.3 \%$ & 0.041 \\
\hline & $P_{H}\left(I_{d} \mid d_{t+1}^{*}, d_{t}\right)$ & [0.065] & {$[0.066]$} & & & & {$[0.016]$} & [0.049] & & & \\
\hline P3. & $\begin{array}{l}\text { Fixed effects Probit } \\
P_{F}\left(I_{d} \mid d_{t+1}^{*}, d_{t}, \alpha_{i}\right)\end{array}$ & - & $\begin{array}{l}2.653^{* * *} \\
{[0.048]}\end{array}$ & 2.91 & $10.5 \%$ & 0.196 & - & $\begin{array}{l}0.928^{* * * *} \\
{[0.024]}\end{array}$ & 4.05 & $3.3 \%$ & 0.279 \\
\hline
\end{tabular}

This table presents the estimation of discrete dependent variable target financing models in the empirical data and simulated samples in which issuance decisions are random. Leverage is measured by the book debt to assets ratio. The issuance indicator $I_{d}$ used in models P1-P3 of Appendix B is equal to one when net debt issues exceeds net equity issues, $n d i>n d e$, and zero otherwise. Target leverage, $d_{t+1}^{*}$, is the fixed effects regression based target presented in Appendix $A$ and leverage deviations are defined as target leverage minus lagged leverage, $\left(d_{t+1}^{*}-d_{t}\right)$. The coefficient $\theta$ is a sensitivity parameter to leverage deviations. The common issuance probability model, P1, is a Logit regression of the issuance indicator on leverage deviations and a constant with a predicted probability of $P_{C}\left(I_{d} \mid d_{t+1}^{*}, d_{t}\right)=1 /\left[1+\exp \left(-\left(\alpha+\theta\left(d_{t+1}^{*}-d_{t}\right)\right)\right)\right]$. The heterogeneous issuance probability model P2 allows for different target leverage for each firm with the added term $\ln \left(\frac{d_{t+1}^{*}}{1-d_{+1}^{*}}\right)$ and the predicted probability is $P_{H}\left(I_{d} \mid d_{t+1}^{*}, d_{t}\right)=1 /\left[1+\exp \left(-\left(\alpha+\delta \ln \left(d_{t+1}^{*} /\right.\right.\right.\right.$ $\left.\left.\left.\left[1-d_{t+1}^{t}\right]\right)+\theta\left(d_{t+1}-d_{t}\right)\right)\right)$, where $\delta$ is the logistic scale parameter. The fixed effects Probit model P3 allows for firm-specific effects $P_{F}\left(I_{d} \mid d_{t+1}^{*}, d_{t}, \alpha_{i}\right)=\Phi\left(\alpha_{i}+\theta\left(d_{t+1}^{*}-d_{t}\right)\right)$ and a common coefficient parameter on leverage deviations. Point estimates and standard errors in brackets from the real data and simulated data are presented. $\Delta P$ is predicted change in probability of issuance given leverage is one standard deviation away from target leverage. The sample consists of 140,731 firm years of U.S. Compustat data spanning 1970-2010. Half-Life $\Lambda$ (Eq. (12)) is calculated using estimated $\theta$, sample average deficit $k=14.7$, and leverage $d^{*}=0.437 .{ }^{* * *}$ is significance at the $1 \%$ level.

\section{References}

Chang, X., Dasgupta, S., 2009. Target behavior and financing: How conclusive is the evidence? J. Finance 64, 1767-1796.

Chen, L., Zhao, X., 2007. Mechanical mean reversion of leverage ratios. Econ. Lett. 95, 223-229.

Dang, V.A., Kim, M., Shin, Y., 2015. In search of robust methods for dynamic panel data models in empirical corporate finance. J. Bank. Finance 53, 84-98. De Jong, A., Kabir, R., Nguyen, T., 2008. Capital structure around the world: The roles of firm- and country-specific determinants. J. Bank. Finance 31, 19541969.

DeAngelo, H., Roll, R., 2015. How stable are corporate capital structures? J. Finance 70 (1), 373-418.

Denis, D., McKeon, S., 2012. Debt financing and financial flexibility evidence from proactive leverage increases. Rev. Financial Stud. 25 (6), $1897-1929$.

Drobetz, W., Wanzenried, G., 2006. What determines the speed of adjustment to the target capital structure? Appl. Financial Econ. $16,941-958$.

Eckbo, B.E., Kisser, M., 2016. Leverage dynamics of high-frequency debt issuers, Dartmouth College working paper.

Elsas, R., Florysiak, D., 2015. Dynamic capital structure adjustment and the impact of fractional dependent variables. J. Financial Quant. Anal. 50 (5), 11051133.

Fama, E., French, K., 2002. Testing tradeoff and pecking order predictions about dividends and debt. Rev. Financial Stud. 15, 1-33.

Fan, J., Titman, S., Twite, G., 2012. An international comparison of capital structures and debt maturity choices. J. Financial Quant. Anal. 47, 23-56.

Faulkender, M., Flannery, M., Hankins, K., Smith, J., 2012. Cash flows and leverage adjustments. J. Financ. Econ. 103 (3), $632-646$.

Fisher, E., Heinkel, R., Zechner, J., 1989. Dynamic capital structure choice: Theory and tests. J. Finance 44, 19-40.

Flannery, M., Rangan, K., 2006. Partial adjustment toward target capital structures. J. Financ. Econ. 79, 469-506.

Flannery, M., Hankins, K., 2013. Estimating dynamic panel models in corporate finance. J. Corporate Financ. 19, 1-19.

Graham, J.R., Harvey, C.R., 2001. The theory and practice of corporate finance: evidence from the field. J. Financ. Econ. 60, 187-243.

Hovakimian, A., 2004. The role of target leverage in security issues and repurchase. J. Bus. 77, 1041-1071.

Hovakimian, A., Li, G., 2012. Is the partial adjustment model a useful tool for capital structure research? Rev. Financ. 16, $733-754$.

Hovakimian, A., Opler, T., Titman, S., 2001. The debt-equity choice. J. Financial Quant. Anal. 36, 1-24.

Huang, R., Ritter, J., 2009. Testing theories of capital structure and estimating the speed of adjustment. J. Financial Quant. Anal. 44, 237-271.

Iliev, P., Welch, l., 2010. Reconciling estimates of the speed of adjustment of leverage ratios. UCLA working paper.

Kayhan, A., Titman, S., 2007. Firms' histories and their capital structures. J. Financ. Econ. 83, 1-32.

leary, M.T. Roberts, M.R., 2005. Do firms rebalance their capital structures? J. Finance 60, 2575-2619.

Lemmon, M., Roberts, M., Zender, J., 2008. Back to the beginning: Persistence and the cross-section of corporate capital structure. J. Financ. 63, 1575-1608.

Matsa, D.A. 2010. Capital structure as a strategic variable: Evidence from collective bargaining. J. Financ. 65 (3), $1197-1232$.

Miller, M.H., 1977. Debt and taxes. J. Financ. 32 (2), 261-275.

Morellec, E., Nikolov, B., Schurhoff, N., 2012. Corporate governance and capital structure dynamics. J. Finnanc. 67 (3), $803-848$.

Mukherjee, T., Wang, W., 2013. Capital structure deviation and speed of adjustment. Financial Rev. 48, 597-615.

Myers, S.C. Majluf, N.S., 1984. Corporate financing and investment decisions when firms have information that investors do not have. J. Financ. Econ. 13 , $187-221$

Oztekin, O., Flannery, M., 2012. Institutional determinants of capital structure adjustment speeds. J. Financ. Econ. 103, 88-112.

Rajan, R.G., Zingales, L., 1995. What do we know about capital structure? Some evidence from international data. J. Financ. 50 (5), $1421-1460$.

Scott, J.H., 1976. A theory of optimal capital structure. Bell J. Econ. 7 (1), 33-54.

Schivdasani, A., Stefanescu, I., 2010. How do pensions affect corporate capital structure decisions? Rev. Financial Stud., 1287-1323

Shyam-Sunder, L., Myers, S., 1999. Testing static tradeoff against pecking order models of capital structure. J. Financ. Econ. 51, 219-244.

Zhou, Q., Tan, K., Faff, R.W., Zhu, Y., 2016. Deviation from target capital structure, cost of equity and speed of adjustment. J. Corporate Financ. forthcoming.

Post-print standardized by MSL Academic Endeavors, the imprint of the Michael Schwartz Library at Cleveland State University, 2020 